\title{
Algunas reflexiones sobre el bronce inicial en el noroeste peninsular. La cuestión del Ilamado horizonte "Montelavar"
}

\author{
DIRK BRANDHERM
}

Ruhr-Universität Bochum

Institut für Archäologische Wissenschaften

Fach Ur- und Frühgeschichte

\begin{abstract}
Resumen
A pesar de una larga historia de investigación, el Bronce Inicial del Noroeste peninsular sigue siendo uno de los fenómenos menos conocidos de la Edad del Bronce en el ámbito geográfico de la Península Ibérica. Hasta el momento, la mayoría de los intentos para caracterizar mejor este período, particularmente la propuesta de un 'horizonte Montelavar' o 'grupo Montelavar', formulada por Harrison hace treinta años, han contado con ciertos problemas conceptuales, lo que efectivamente ha inhibido su consideración unánime por parte de la investigación posterior. En el presente artículo emprendemos una sistematización sobre todo del registro funerario durante el Bronce Inicial del sector noroccidental de la Península Ibérica desde una nueva perspectiva, prestando particular atención al papel de la región dentro de la red de comunicación interregional que caracteriza el Bronce Inicial en la fachada atlántica.
\end{abstract}

Palabras claves: Bronce Antiguo. Península Ibérica. Horizonte Montelavar.

\section{Abstract}

Although considerable effort has gone into the study of the subject, the Early Bronze Age of northwestern Iberia remains one of the more poorly understood phenomena of the Iberian Bronze Age. Most past attempts to systemise the relevant archaeological evidence did suffer from certain conceptual problems, particulary Harrison's notion of a 'Montelavar horizon' or 'Montelavar group', formulated thirty years ago. As a consequence, neither this nor any of the other concepts which have been put forward in the past, has ever been embraced by a majority of scholars. In the present article, we are trying to solve at least some of the problems that plagued earlier concepts, by taking a fresh look at the Early Bronze Age funerary record from northwestern Iberia. At the same time, we are looking at the role played by Galicia and northern Portugal in the network of interregional contacts which characterize the Early Bronze Age in Western Europe.

Keywords: Early Bronze Age. Iberian Peninsula. Montelavar Group.

Pocos fenómenos en el registro arqueológico de la Prehistoria reciente peninsular presentan al mismo tiempo una relativa abundancia de restos, y tantos problemas en su caracterización cultural,

1 Este articulo presenta los resultados de un estudio realizado por el autor mientras estuvo como becario de investigación en el departamento de Prehistoria y Arqueología de la UAM durante los años 2001-2002, con financiación por la Deutsche Forschungsgemeinschaft (Brandherm 2001 b; idem 2002). como los vestigios del Bronce Inicial en el sector noroccidental de la Península Ibérica, o sea en Galicia y en Portugal al norte del Duero ${ }^{1}$.

Muchos son los autores que desde las obras pio-

Queremos además expresar nuestro agradecimiento a Ignacio Montero por su inestimable ayuda en mejorar nuestro deficiente castellano. Lógicamente, la responsabilidad de todos los errores y defectos que pueda sufrir el presente texto queda exclusivamente con quien lo firma. 
neras de López Cuevillas y Bouza Brey han avanzado y sintetizado nuestros respectivos conocimientos, pero sigue siendo difícil la definición coherente de entidades culturales para el Bronce Inicial y el Bronce Medio del Noroeste ${ }^{2}$, aún mucho más que para el Bronce Final de la fachada atlántica peninsular. Los distintos enfoques que se encuentran en la bibliografía actual llegan desde propuestas formuladas a partir de un marco histórico-cultural a otras que rechazan el lenguaje de estas como construcción artificial que no facilita, pero más bien dificulta la comprensión de procesos (pre-)históricos.

En concreto, la propuesta del llamado 'horizonte Montelavar', formulada por Harrison ${ }^{3}$ en 1974 bajo un enfoque histórico-cultural, a pesar de la justificada crítica por parte de algunos autores ${ }^{4}$, en general sigue siendo un concepto que ha contado con bastante aceptación, pero sobre el que se ha reflexionado poco 5 . No pretendemos aumentar aquí la discusión epistemológica con respecto a la validez del enfoque histórico-cultural como tal, sino que nuestro objetivo será más bien revisar la propuesta de Harrison, nada más ni nada menos que dentro su propio marco de referencia teórico. Considerando los avances de la investigación empírica durante los últimos treinta años, y dado que los problemas subliminales inherentes al concepto de este horizonte llevaron a su rotundo rechazo por parte de la investigación, una reconsideración detallada de su propia base nos parece no solo plenamente justificada, sino incluso muy necesaria.

Según Harrison, durante el Bronce Inicial el 'horizonte Montelavar' habría sustituido al campaniforme en muchas regiones del Occidente peninsular. Su característica principal sería la combinación de puñales de lengüeta con dos o más puntas Palmela y posiblemente con otros objetos metálicos, pertenecientes a una tipología previamente conocida en contextos campaniformes, pero sin cerámica, o exclusivamente asociados a cerámica lisa como ajuar de sepulturas individuales ${ }^{6}$. Como hallazgo epónimo para este grupo u horizonte se consideró la sepultura de Pera Gorda ${ }^{7}$ en la Estremadura portu- guesa, siendo Montelavar la sede de la feligresía correspondiente.

Desde el inicio quedaron irresueltos algunos problemas de delimitación, tanto del aspecto formal de la definición como del aspecto geográfico del 'Horizonte Montelavar'. Por un lado ajuares con puñales de lengüeta pero sin puntas Palmela no entran en su definición, como tampoco entran sepulturas que contienen puntas asociadas a la respectiva cerámica, pero no puñales. Este problema fue reconocido ya en un inicio por el propio Harrison, quien trató de resolverlo con la introducción de un grupo de 'hallazgos relacionados'. Sin embargo dudamos que sus criterios se adapten de una manera adecuada a la realidad del registro arqueológico. Por otro lado nos vemos enfrentados a la cuestión del área a la cual es aplicable esta definición. El concepto original del horizonte Montelavar reclamaba validez para la mayor parte de la mitad occidental de la Península Ibérica, excepto las partes del Suroeste donde el horizonte Ferradeira, definido por Schubart ${ }^{8}$ con anterioridad al estudio de Harrison, representa la tradición funeraria del Bronce Inicial. Sin embargo a algunos de los ajuares que se incluyeron en el grupo de las sepulturas 'Montelavar' según su definición original resultan por lo menos cuestionables.

Así, la propia sepultura epónima de Pera Gorda, cuando fue documentada por Nogueira y Zbyszewski ${ }^{9}$, ya se encontraba parcialmente destruida y saqueada por los obreros de la cantera en que apareció. Se sabe que algún elemento del ajuar metálico ya había desaparecido, y como los restos entonces conservados nunca fueron objeto de una excavación sistemática, no se puede descartar por completo que hubiesen existido elementos cerámicos bien al interior, bien al exterior de la cámara.

Del mismo modo resulta cuestionable la inclusión de la sepultura de Montilla (Córdoba) en el grupo de los ajuares 'Montelavar'. Sabemos que en este caso hubo cerámica formando parte del ajuar, pero que no fue recuperada en su momento ${ }^{10}$. Por tanto no es posible hacer afirmaciones sobre el

2 López Cuevillas 1925. 1933. 1955. 1956. 1959; Bouza Brey 1927; López Cuevillas / Bouza Brey 1929. 1931; MacWhite 1951; Monteagudo 1953. 1981; Harbison 1967; Ruiz-Gálvez Priego 1979. 1984; Criado Boado / Vázquez Varela 1982; Jorge 1986. 1988. 1999; Sanches 1992. 1997; Meijide Cameselle 1994; Bettencourt 1997; Comendador Rey 1998. 2001; Fábregas Valcarce 1998; Prieto Martínez 1999; Suárez Otero 2002.

3 Harrison 1974 a. 1974 b.

5 Ruiz-Gálvez Priego 1979, 152; eadem 1984, 541 s.; Silva / Lopes / Maciel 1981, 54; Jorge 1988, 89; Almagro Gorbea $1995,139$.

6 Harrison 1974 a, 84-90.

7 Nogueira / Zbyszewski 1943, 95-97.

8 Schubart 1971, 195-215.

9 Nogueira / Zbyszewski 1943, 95 s.

10 Cabré Aguiló 1915-20, 540.

4 Jorge 1986, 876; Fábregas Valcarce 1995 a, 107. 
numero y el carácter de los vasos que acompañaron el puñal de cobre y los ornamentos de oro. No obstante estas dificultades, Harrison ${ }^{11}$ incorporó el ajuar de Montilla en su grupo 'Montelavar', presuponiendo que se trataba de cerámica lisa. Otros autores, sin embargo, han opinado que este ajuar pudo haber tenido cerámica campaniforme ${ }^{12}$.

Un problema similar lo presenta el hallazgo de Cañada Rosal (Écija, Sevilla), donde Harrison ${ }^{13}$ adscribió la cerámica lisa y los elementos metálicos a un ajuar y la cerámica campaniforme a otro, aunque la situación en que se encontraron los materiales no ofrece indicios para suponer la existencia de dos sepulturas distintas.

Otro elemento que contribuye a las problemas que presenta el concepto original del horizonte 'Montelavar' es la inclusión de depósitos no funera$\operatorname{rios}^{14}$. Mientras que difícilmente se puede negar el posible significado cronológico de la ausencia de cerámica campaniforme en sepulturas que contienen un ajuar metálico generalmente asociado al campaniforme, en ningún momento esta cerámica fue un elemento habitual en los depósitos no funerarios. No hay entonces ningún argumento con que razonar en términos de una cronología relativa la posterioridad de tales depósitos con respecto a las tumbas campaniformes.

Tampoco constituye necesariamente un rasgo cronológico la relativa riqueza de las sepulturas del horizonte 'Montelavar' en elementos de oro frente a las sepulturas campaniformes del Occidente peninsular, como fue interpretado por el propio Harrison ${ }^{15}$. Incluso si suponemos que en la sepultura de Montilla no hubo cerámica campaniforme que acompañara la diadema y los dos brazaletes de oro, los enterramientos de Perro Alto (Fuente Olmedo, Valladolid) $^{16}$ y Torre Águila (Montijo, Badajoz) $)^{17}$, dados a conocer después de que Harrison formulara el concepto del horizonte 'Montelavar', han demonstrado que también se conocen en contextos campaniformes ajuares igual o más ricos.

Si excluimos -por el momento- tanto los enterramientos con documentación incompleta como también los depósitos que sirvieron a Harrison para su

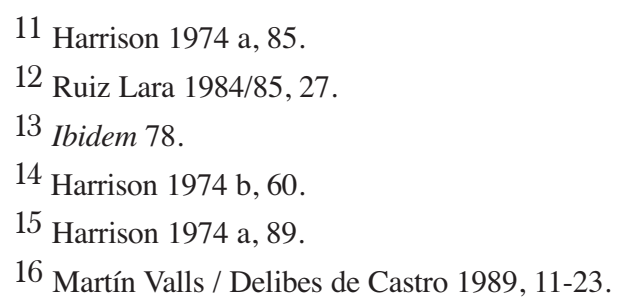

definición del grupo 'Montelavar', podemos observar que casi todos los hallazgos restantes se concentran en el Noroeste peninsular, tratándose de enterramientos bajo túmulo o en cista. Con menor frecuencia aparecen enterramientos del Bronce Inicial en tumbas megalíticas del Neolítico o Calcolítico. Al contrario de la situación en otras regiones, ninguno de los ajuares incluidos por Harrison en su grupo 'Montelavar' se encontró en una fosa simple, forma de enterramiento habitual para los grupos campaniformes en la Meseta y en la cuenca del Guadalquivir.

Tampoco estas diferencias se deben interpretar necesariamente en un sentido cronológico. La tradición de enterramientos individuales bajo túmulo en el Noroeste tiene su origen ya en la primera mitad del III ${ }^{\text {er }}$ milenio a.C ${ }^{18}$. Por otra parte, y en comparación con zonas limítrofes, los ajuares con cerámica campaniforme no son muy frecuentes en ninguna parte del Noroeste peninsular, ni tan siquiera la cerámica como tal constituye un elemento muy común en las tumbas colectivas e individuales del Neolítico y Calcolítico de la región. Así las condiciones culturales para la inclusión del campaniforme en los ritos funerarios aquí se presentan muy distintas de la situación que encontramos en otras regiones donde ya en épocas inmediatamente anteriores la cerámica constituye un elemento integral de los ajuares fune$\operatorname{rarios}^{19}$.

De todos modos, la aparente ausencia de cerámica en los ajuares de enterramientos bajo túmulo del Noroeste constatada en muchas excavaciones antiguas, debe ser tomada con alguna cautela según investigaciones más recientes. Criado Boado y Vázquez Varela ${ }^{20}$ todavía en su momento interpretaron la presencia de cerámica campaniforme en la masa del túmulo, fuera de la propia cámara, como resultado de alteraciones posteriores, pero excavaciones como la del túmulo 1 de la Chã de Carvalhal (Grilo, conc. Baião, Douro Litoral) han demonstrado que durante el curso de los ritos funerarios la cerámica -tanto lisa como campaniforme decoradafue rota intencionalmente y depositada en las capas exteriores del túmulo. En este caso peculiar también se halló un cuenco Palmela en el interior de la cáma-

17 Brandherm 2003, 132 s. 135 nos. 245. 253.

18 Cruz 1995, 104-110; Fábregas Valcarce 1995 b, 85-90. Para la correspondiente situación en zonas limítrofes de la Submeseta Norte véase Harrison / Mederos Martín 2001, 115120.

19 Fábregas Valcarce 1995 a, 100 s.; Suárez Otero 2005, 179.

20 Criado Boado / Vázquez Varela 1982, 56-58. 
ra. El ajuar metálico, dos puñales de lengüeta y cuatro puntas Palmela, estaba por el contrario depositado al exterior de la cámara, en la base del revestimiento de piedras ${ }^{21}$. En una excavación antigua que solamente perseguía recuperar el ajuar de la cámara, todos los elementos del exterior -la cerámica fragmentada de las capas superiores tanto como la combinación de elementos metálicos tipo 'Montelavar' el revestimiento de piedras- con toda probabilidad hubiesen escapado el descubrimiento y la documentación por parte de los arqueólogos.

Eso no quiere decir que todos los hallazgos utilizados por Harrison para la definición de su horizonte 'Montelavar' sean en realidad enterramientos campaniformes con la cerámica depositada al exterior de la cámara. Sin embargo, parece obvio que la presencia de puñales de lengüeta o puntas Palmela en enterramientos sin asociación a cerámica campaniforme en el interior de la cámara por si mismo no constituye un argumento suficiente para presumir una diferencia cronológica en relación a ajuares campaniformes 'verdaderos'. Tratamos más bien con un fenómeno cultural que se articula a través de un rito funerario específico y distinto del de los grupos campaniformes 'normales'. Si estas diferencias también indican una distancia cronológica es una cuestión aparte, cuya respuesta debe ser razonada independientemente.

Dejando por el momento de lado posibles implicaciones para una cronología relativa más detallada, podemos resumir los rasgos fundamentales de los enterramientos del Bronce Inicial en el Noroeste peninsular de la siguiente manera:

- Enterramientos individuales bajo túmulo con o sin revestimiento pétreo o en cistas no cubiertas por construcciones tumulares,

- Ajuares compuestos por puñales (mayoritariamente de lengüeta) y/o puntas Palmela,

- Ausencia de elementos cerámicos en los ajuares o presencia sólo de cerámica lisa o de cerámica decorada separada del ajuar metálico de la cámara,

- Riqueza de algunos ajuares en adornos de oro.

Cierto que en cuanto al rito de enterramiento individual tenemos que tener presente que los suelos ácidos comunes en la mayor parte de Galicia y el norte de Portugal no favorecen mucho la conservación del material óseo. Por eso casi siempre son sólo las dimensiones de la cámara, la composición del ajuar y la disposición de sus elementos que permiten deducir el número de muertos en una sepultura. De este modo no se pueden reconocer fenómenos como enterramientos parciales o secundarios, bien conocidos en el Bronce Inicial de otras regiones donde hay condiciones de preservación más favorables ${ }^{22}$. Con todo, la presencia de construcciones cistoides de muy reducidas dimensiones y ocasionalmente de cenizas -muy raramente también de hueso quemado- atestigua que durante el Bronce Inicial no sólo se practicó la inhumación, sino que en un cierto número de casos también la cremación.

Tanto cistas como túmulos forman, en la mayoría de los casos, pequeñas agrupaciones. Por el contrario, no se conocen verdaderas necrópolis del Bronce Inicial en el Noroeste peninsular. De todas formas, los túmulos de la Edad del Bronce algunas veces se agrupan en extensos paisajes funerarios de más de un centenar de monumentos, como por ejemplo en Vilavella (La Coruña) o en la Serra da Aboboreira (Douro Litoral). En estos casos se trata de necrópolis cuyo origen se remonta hasta el Neolítico, con monumentos construidos a lo largo de más de dos milenios, de los cuales sólo una minoría pertenece a la Edad del Bronce.

Frente a las tumbas colectivas del Neolítico, los túmulos de la Edad del Bronce casi siempre se distinguen por sus dimensiones bastante más reducidas. La mayoría de los monumentos hoy por hoy alcanza una altura máxima de 0,5 m y un diámetro máximo de $10 \mathrm{~m}$; son sumamente raros túmulos con un diámetro mayor o una altura actual de más de $1 \mathrm{~m} .{ }^{23}$ Como ya ocurría en el caso de los monumentos neolíticos, las construcciones tumulares de la Edad del Bronce demuestran una enorme variabilidad arquitectónica. Se conocen construcciones tumulares con y sin elementos pétreos, como revestimientos o cámaras y delimitaciones exteriores del túmulo ${ }^{24}$. Menos frecuente es el caso del túmulo coronado por un bloque monolítico al modo de estela ${ }^{25}$. Como la gran mayoría de los ajuares funerarios conocidos actualmente procede de excavaciones antiguas y sin documentación adecuada, resulta difícil identificar patrones en la

\footnotetext{
21 Cruz 1992, 32-45.

22 Fabián García 1992, 106-108.

23 Silva 1997, 611-613 fig. 6.
}

24 Ibidem 613-615.

25 Sanches / Botelho / Silva 1990/91, 42-45; Vaquero Lastres 1995 b, 406 lám. 2. 
relación entre el tipo de construcción de la tumbas y los ajuares.

Sólo en los últimos años la investigación ha prestado atención a la posible existencia de inhumaciones en fosas durante el Bronce Inicial del Noroeste. En la excavación de la necrópolis de cistas del Agro de Nogueira (Toques, La Coruña) se detectó una serie de fosas, en su mayoría de forma ovalada, que por sus dimensiones bien pudieran haber servido para la inhumación de cadáveres totalmente desaparecidos en la actualidad debido al carácter agresivo de los suelos ácidos ${ }^{26}$. En todo

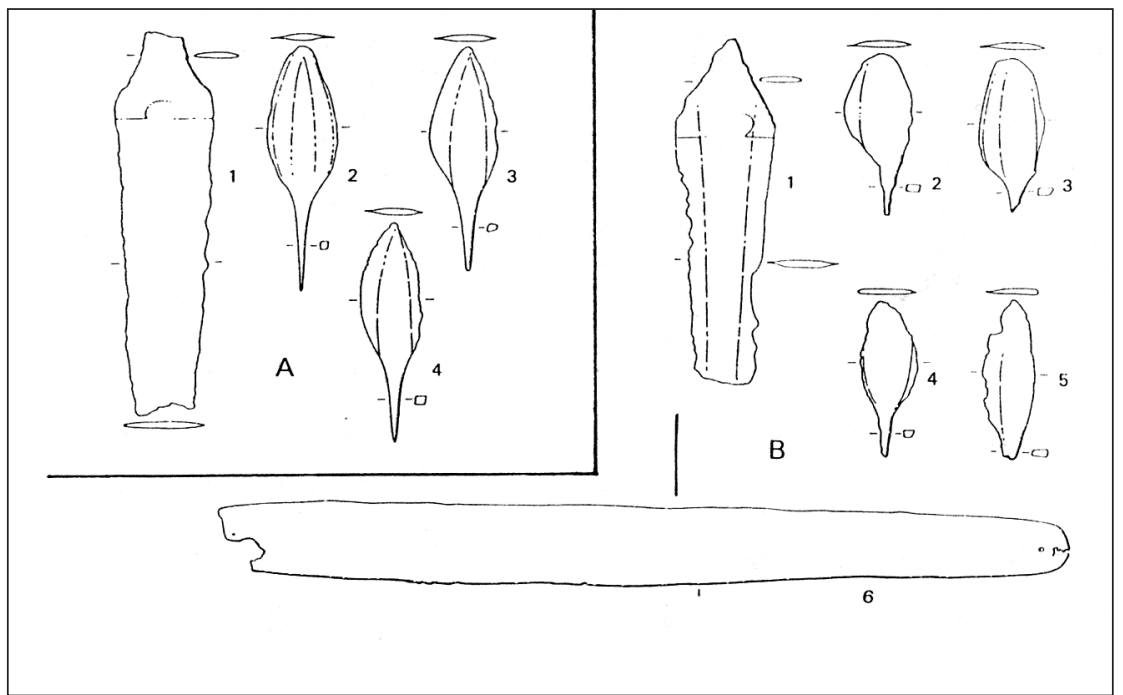

Fig 1. A Monte das Cabras (Lalín, Pontevedra); B Vilavella (Puentes de García Rodríguez, La Coruña), túmulo 240 Esc 1:4

caso, frente a la total ausencia de elementos de ajuar en estas fosas, su interpretación como tumbas no se puede considerar más que una mera hipótesis. Efectivamente, para las fosas del Agro de Nogueira tampoco se pueden descartar otras funciones relacionadas con la utilización de la necrópolis.

La gama de elementos de ajuar que caracterizan el círculo de ritos funerarios del Noroeste durante el Bronce Inicial presenta una diversidad muy limitada. Mayortariamente se trata de objetos de las categorías arriba mencionadas: puñales de lengüeta y puntas Palmela, cerámica lisa y adornos de oro $^{27}$. Como elementos de ajuar por lo demás poco comunes en el Bronce Inicial del Noroeste se conocen brazaletes de arquero en sepulturas de Pedra Marrada (Carnota, La Coruña) ${ }^{28}$, Chã de Arefe (Durrães, conc. Barcelos, Minho) ${ }^{29}$ y Vilar

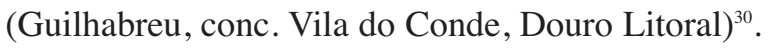

Con el fin de evitar confusiones con el concepto del 'grupo Montelavar' según Harrison y sus problemas de definición, para referirnos a este fenóme-

26 Meijide Cameselle 1994, 210 s.; idem 1995, 85-88.

27 El concepto del 'círculo de ritos funerarios' o 'Grabsittenkreis' fue introducida en la bibliografía por Eggers 1950,1-3. El término se acuñó con referencia al concepto del 'círculo cultural' o 'Kulturkreis', haciendo referencia a los ritos funerarios como subsistema cultural.

28 Ruiz-Gálvez Priego 1979, 153.

29 Silva / Lopes / Maciel 1981, 50-52. Además de la combinación de una punta Palmela y un brazal de arquero de la sepultura 1 de Chã de Arefe, otro brazal de arquero acompañaba como único ajuar a la sepultura 2 del mismo yacimiento.

30 Jorge 1988, 89. Otro brazal de arquero procede de la cista 2 de Gandón (Cangas de Morazzo, Pontevedra). En el caso de no aquí queremos proponer el termino del 'grupo Vilavella-Atios'. En este contexto hay que destacar que la referencia a un 'grupo' en nuestro caso no implica el concepto de una cultura arqueológica, sino que sólo se refiere a un círculo de ritos funerarios. El monumento 240 de Vilavella (Puentes de García Rodríguez, La Coruña) ${ }^{31}$ sería epónimo para los ajuares con puñal de lengüeta y puntas Palmela, así como para inhumaciones bajo túmulo (fig. 1), la sepultura de Atios (Porriño, Pontevedra) ${ }^{32}$ por el contrario daría nombre a la facies de los ajuares con puñal, pero sin puntas Palmela, acompañando inhumaciones en cista (fig. 2).

El único ajuar que no encaja bien en la diferenciación de estas dos facies es el de la tumba de São Bento (Balugães, conc. Barcelos, Minho) ${ }^{33}$, cuyo tipo de construcción quedó prácticamente sin documentar. Según las informaciones disponibles, no parecen haber existido vestigios de un túmulo, pero desconocemos si los elementos del ajuar proceden de una cista, de una fosa simple o de otro tipo de

un fragmento de cobre de la misma cista parece tratarse no del resto de un puñal o de una punta Palmela, pero más bien de un colgante discoide. De todos modos, el deficiente estado de conservación de la pieza no permite una conclusión definitiva. Por lo tanto, no hemos incluido este enterramiento en nuestro catálogo de sepulturas del grupo Vilavella-Atios (fig. 3). Sin embargo, tanto esta sepultura como la vecina cista 1, probablemente un enterramiento infantil, parecen estrechamente vinculados a este circulo de ritos funerarios (véase Peña Santos 1985, 82 fig. 7).

31 Iglesia 1907, 62-64.

32 Álvarez Blásquez / Acuña Castroviejo / García Martínez 1970, 22-26.

33 Estacio da Veiga 1891, 46 lám. 4. 


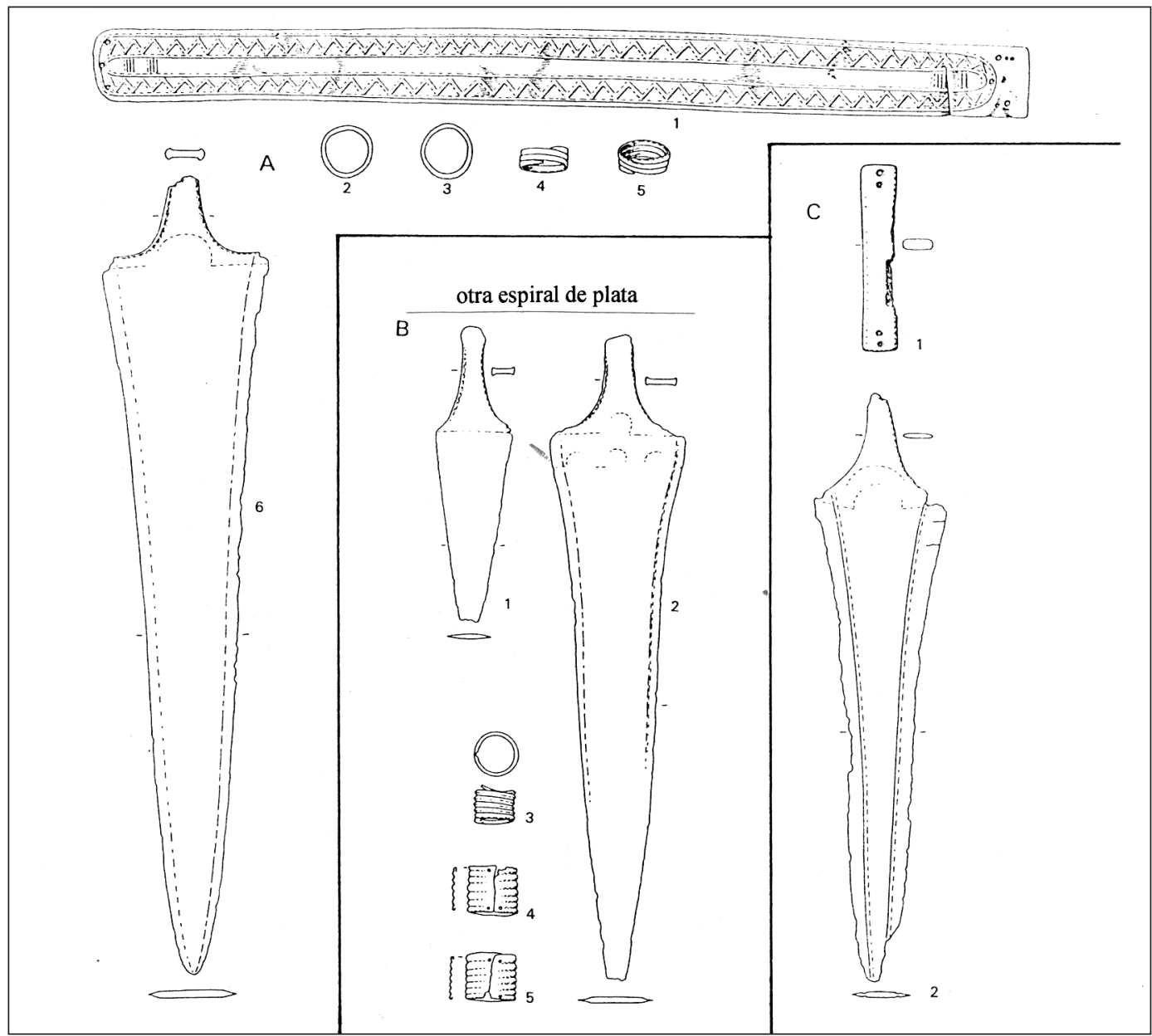

Fig 2. A Quinta da Agua Branca (Lobelhe, conc. Vila Nova da Cerveira, Minho); B Atios (Porriño, Pontevedra); C Pedra Marrada (Carnota, La Coruña). Esc 1:4

construcción subterránea. Además de una gargantilla de tiras de oro, hay tres puntas Palmela y noticias de una cuarta, desaparecida, de la cual no se puede descartar que en realidad se tratase de un pequeño puñal de lengüeta.

Por lo demás no se conocen puntas Palmela procedentes de cistas en el grupo Vilavella-Atios, si bien es verdad que las cistas de la facies Atios en comparación con los túmulos destacan por su relativa abundancia de metales preciosos. Tanto la cista epónima de Atios como la de la Quinta de Agua Branca (Lobelhe, conc. Vila Nova de Cerveira, Minho $)^{34}$ contenían varios objetos de oro y en algún caso de plata. De una cista de Lagares (Vale Bemfeito, conc. Macedo de Cavaleiros, Trás-os-

\footnotetext{
34 Fortes 1906 a, 241-252.
}

35 Alves 1934, 684 s.; véase también Pingel 1992, 288 nº. 235, donde erróneamente se menciona como 'circunstancias del hallazgo desconocidas'. Cuando en el año 1934 se investigó el yacimiento, la cista respectiva ya se había destruida por completo. De todas maneras, a pocos metros se encontró otra cista, también violada ya por los vecinos del lugar, según
Montes e Alto Douro) $)^{35}$, que en el momento de su documentación por J. J. Vaz de Morais de Abreu Sarmento sobre el año 1904 ya se encontraba violada, aparte de algunos fragmentos de cerámica gruesa se recuperó una espiral de oro con tres vueltas, hoy desaparecida también. Una espiral de plata similar al ejemplar conservado de Atios se conoce como único elemento de ajuar de una cista violada de Pedrosa (Cualedro, Orense) ${ }^{36}$.

Por otra parte, el único objeto de oro procedente de una sepultura de la facies Vilavella lo constituye la diadema del monumento 240 de la necrópolis epónima (fig. $1 \mathrm{~B}, 6$ ), faltando por completo objetos de plata en los túmulos de esta facies. En este respecto resulta muy lamentable la deficiente informa-

cuyos indicaciones se habían descubierto más cistas en ocasiones anteriores. La única información disponible sobre sus respectivos ajuares consiste en que su venta proporcionó una riqueza inesperada a una familia del pueblo (Alves 1938, 276).

36 Rodríguez-Colmenero / Delibes de Castro 1976, 181 s. fig. 2 lám. 2, 1 . 
ción disponible sobre las circunstancias de hallazgo de un excepcional conjunto de piezas de oro de Cícere (Santa Comba, La Coruña) ${ }^{37}$. La gargantilla de tiras y las dos diademas, que se asemejan bastante a las piezas de São Bento y de Vilavella, supuestamente se hallaron en una 'mamoa', pero desconocemos si en un origen iban asociadas a elementos diagnósticos del circulo de ritos funerarios Vilavella-Atios, como por ejemplo un puñal o puntas de Palmela. En tal caso lógicamente habría que replantearse la caracterización de la facies Vilavella como más pobre en elementos de oro que la facies Atios, pero la falta de información más detallada, al igual que en el caso de la cista arriba mencionada de Lagares y de otros ajuares de composición mal documentada, nos obliga a excluir este conjunto de la estadística de las dos facies. La siguiente tabla entonces reúne todas las sepulturas y sus respectivos ajuares que según nuestros criterios habría que incluir en el circulo de ritos funerarios VilavellaAtios (fig. 3) 38. $^{38}$

Debido al número limitado de conjuntos y tipos en cuestión, resulta sumamente difícil establecer por seriación u otros métodos estadísticos- en qué medida las diferencias entre las dos facies responden a criterios cronológicos. En todo caso, los puñales de lengüieta que se hallan en las cistas de la facies Atios, sin excepción corresponden a formas tardías, en cuanto las piezas procedentes de los túmulos de la facies Vilavella representan una cronología más heterogénea ${ }^{39}$. Aunque eso parece indicar una cierta tendencia cronológica, en el estado actual de la cuestión no es posible atribuir las dos facies de sepulturas a distintas fases cronológicas, como tampoco parece adecuado una subdivisión espacial del área del grupo según criterios geográfico-culturales (fig. 4$)^{40}$.

La falta de ajuares en las sepulturas del Noroeste peninsular que pudieran atribuirse al Bronce Medio, de ningún modo debe ser equiparada a una ausencia de vestigios funerarios en el registro arqueológico durante el período que sigue al Bronce Inicial. Más

37 Monteagudo 1953, 292-294 figs. 31. 32; Pingel 1992, 238 $\mathrm{n}^{\circ} .60$.

38 El sistema empleado en la fig. 3 para indicar la calidad de la documentación de un hallazgo sigue la propuesta de Havel 1978, 114. No hemos incluido en nuestro listado hallazgos que caen en su categoría 4, como por ejemplo el de Pena Corneira (Leiro, Orense), de carácter funerario dudoso (véase Rodríguez-Colmenero / Delibes de Castro 1973, 5254). La clasificación de los puñales de lengüeta sigue Brandherm 2003, 107-163.

39 Brandherm 2003, 139-149. El citado estudio tipológico de los puñales de lengüeta procedentes de contextos funerarios bien son sepulturas -entre ellas cada vez más cremaciones- sin ajuar, que toman el lugar de las tumbas suntuarias del grupo Vilavella-Atios. En su mayoría se trata de túmulos, escaseando las cistas ${ }^{41}$.

Como al menos algunas de las sepulturas con rito de cremación parecen remontarse al Bronce Inicial, y dado que faltan los equivalentes femeninos a los ajuares masculinos del grupo Vilavella-Atios, hay que preguntarse si estamos delante una situación comparable a la que encontramos en otras regiones de la fachada atlántica, sobre todo en el sur de Inglaterra. Ahí, durante la fase Wessex I, la mayoría de los ricos ajuares masculinos se halla con inhumaciones, y en el caso de las sepulturas femeninas invariablemente se trata de cremaciones, generalizándose este rito entre las sepulturas masculinas sólo a partir de la fase Wessex II ${ }^{42}$.

Debido a los suelos ácidos y a la deficiente documentación de muchas de las excavaciones antiguas de los siglos XVIII y XIX, en la Bretaña francesa, la situación se presenta menos clara. De todos modos, la inhumación sin duda fue el rito dominante durante el tercer y la mayor parte del segundo milenio $\mathrm{AC}^{43}$. No obstante, en La Chapelle-de-l'Iff (Languenan, dép. Côtes-du Nord), cerámica del mismo tipo que se encuentra en los túmulos del Bronce Medio apareció junto con cenizas humanas en una fosa circular, fechado por el ${ }^{14} \mathrm{C}$ en los últimos momentos del Bronce Medio o incluso ya en el Bronce Final ${ }^{44}$. También parecen apuntar a un descenso del rito de inhumación las pequeñas construcciones al modo de cistas o 'a tombelle', que durante el Bronce Medio se hacen cada vez más frecuentes, con sus dimensiones reducidas, aunque son muy pocos los casos en que se han podido documentar restos de cremación ${ }^{45}$.

No hay disponibles actualmente indicios para postular en la Bretaña francesa una diferenciación entre inhumaciones y cremaciones según el sexo del difunto, como se ha observado en el caso de Wessex. Los ajuares muchas veces son poco informativos y

del Noroeste también ha podido demostrar que como regla general no se trata de los mismos tipos que aparecen en las sepulturas campaniformes de la Meseta, al contrario de lo que mantiene Harrison 1974 a, 89.

40 Fábregas Valcarce 1995 b, 85 s.

41 idem 1993, 195-200.

42 Gerloff 1975, 232-234.

43 Briard / Le Goffic / Onnee 1994, 55; Needham 2000 a, 153.

44 Briard 1984, 164-166.

45 Briard / Le Goffic / Onnee 1994, 57.

45 Meijide Cameselle 1994, 211 fig. 58. 


\begin{tabular}{|c|c|c|c|c|c|c|c|c|c|c|c|c|c|c|}
\hline & & onstr & uccic & & & & & & & & Aju & & & \\
\hline Yacimiento & 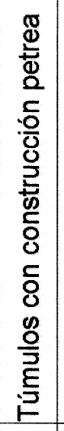 & 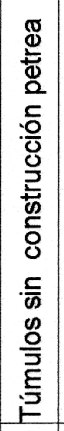 & 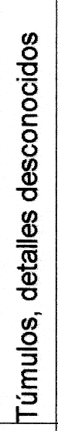 & 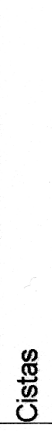 & & 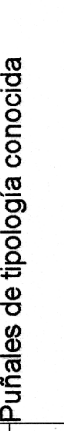 & 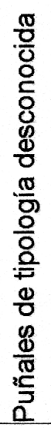 & 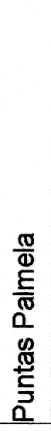 & 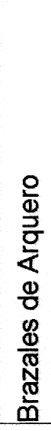 & 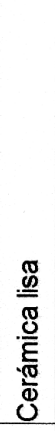 & 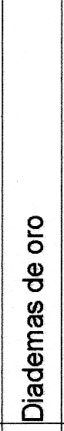 & 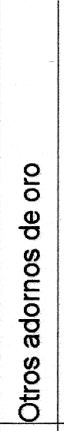 & $\begin{array}{l}\text { Otros elementos } \\
\text { del ajuar }\end{array}$ & 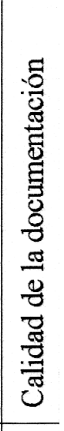 \\
\hline Monte de Penamá & $\bullet$ & & & & & & $\bullet$ & & & & & & & 3 \\
\hline Parxubeira (túmulo 4) & $\bullet$ & & & & & & & $\bullet$ & & $\bullet$ & & & lámina de silex & $1 \mathrm{C}$ \\
\hline Parxubeira (túmulo 2) & $\bullet$ & & & & & & & $\bullet$ & & $\bullet$ & & & cerámica campaniforme & $1 \mathrm{C}$ \\
\hline $\begin{array}{l}\text { Chã de Carvalhal } \\
\text { (túmulo 1) }\end{array}$ & $\bullet$ & & & & L8 & T & & $\bullet$ & & & & & $\begin{array}{l}\text { cerámica campaniforme, } \\
\text { bolas de piedra }\end{array}$ & $1 \mathrm{C}$ \\
\hline Pera Gorda & $\bullet$ & & & & N1 & & & $\bullet$ & & & & & $\begin{array}{l}\text { objeto de cobre o bronce } \\
\text { de forma desconocida }\end{array}$ & $2 \mathrm{C}$ \\
\hline Monte das Cabras & & $\bullet$ & & & L7 & & & $\bullet$ & & & & & & $2 \mathrm{C}$ \\
\hline Vilavella (túmulo 240) & & $\bullet$ & & & L7 & & & $\bullet$ & & & $\bullet$ & & & $2 \mathrm{C}$ \\
\hline Boel & & & $\bullet$ & & & & $\bullet$ & & & & & & & 3 \\
\hline Pena Coba & & & $\bullet$ & & & & $\bullet$ & & & & & & & 3 \\
\hline Vilar & & & $\bullet$ & & & & & $\bullet$ & $\bullet$ & & & & & 3 \\
\hline Chã de Arefe (cista 1) & & & & $\bullet$ & & & & $\bullet$ & $\bullet$ & $\bullet$ & & & & $1 \mathrm{C}$ \\
\hline As Antas & & & & $\bullet$ & & & $\bullet$ & & & $\bullet$ & & & & $2 \mathrm{C}$ \\
\hline Tarayo & & & & $\bullet$ & L4 & & & & & $\bullet$ & & & $\begin{array}{l}\text { lasca de cuarcita, } \\
\text { botón orgánico }\end{array}$ & $2 \mathrm{C}$ \\
\hline Santa Comba & & & & $\bullet$ & $\mathrm{P} 1$ & & & & & & & & & 3 \\
\hline Pedra Marrada & & & & $\bullet$ & P1 & & & & $\bullet$ & & & & & $2 \mathrm{C}$ \\
\hline Atios & & & & $\bullet$ & P2 & 02 & & & & & & $\bullet$ & $\begin{array}{l}\text { espirales de plata, } \\
\text { bloque de cuarcita }\end{array}$ & $1 \mathrm{C}$ \\
\hline Quinta da Agua Branca & & & & $\bullet$ & P2 & & & & & & - & - & & $1 \mathrm{C}$ \\
\hline São Bento & & & & $\bullet$ & & & & $\bullet$ & & & & $\bullet$ & & 3 \\
\hline
\end{tabular}

Fig 3. Enterramientos del circulo de ritos funerarios Vilavella-Atios

faltan análisis antropológicos de las cenizas. Para el Noroeste peninsular, el único caso de cenizas analizadas bajo este aspecto, se refiere a restos que proceden de una pequeña construcción cistoide del Agro de Nogueira. Con gran probabilidad se trata de un individuo femenino ${ }^{46}$, por lo cual no se puede descartar la posibilidad de una bi-ritualidad similar a la que se puede observar en el caso de Wessex y posiblemente de otras regiones atlánticas también. De todas formas es un aspecto que en el futuro necesitará una mayor atención por parte de la investigación, más todavía si tenemos en cuenta las nuevas posibilidades de obtener del hueso cremado dataciones radiocarbónicas de alta precisión ${ }^{47}$.

Otro elemento común que une las tres regiones en cuestión es la relación de los círculos de ritos 


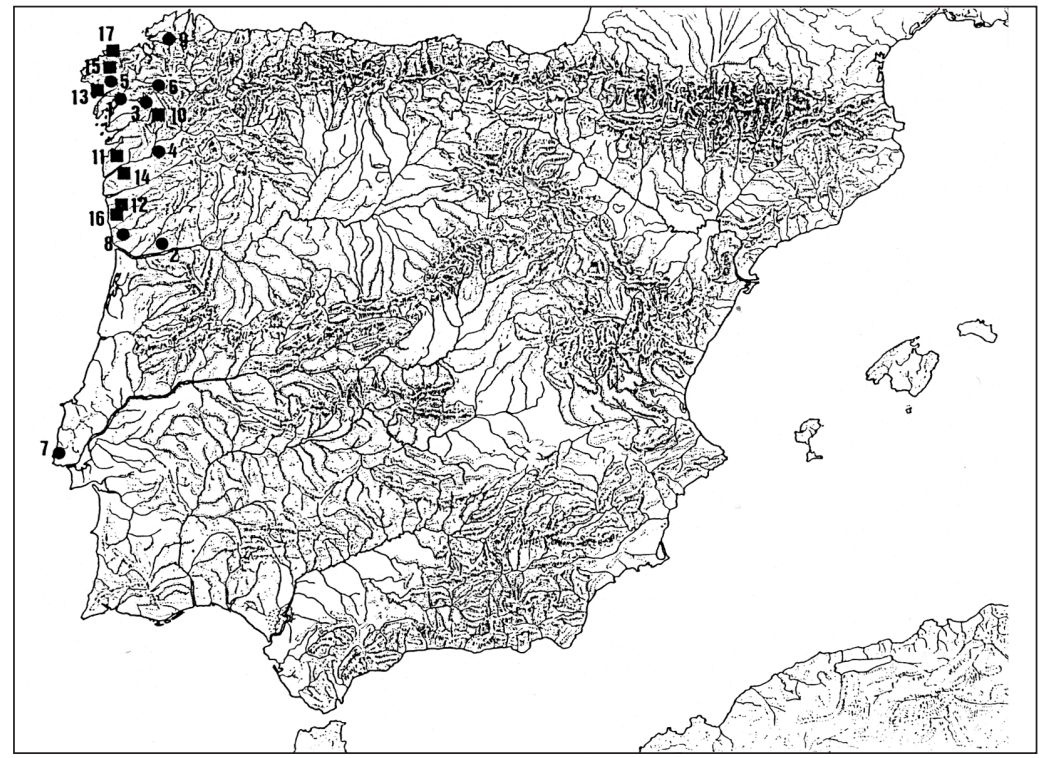

Fig 4. Dispersión geográfica de las sepulturas de la facies Vilavella (circulos) y de la facies Atios (cuadrados), los números se refieren al catálogo del apéndice

funerarios de Wessex, de la Bretaña y del Noroeste peninsular con grupos campaniformes. Los tres círculos de ritos funerarios se distinguen por rasgos similares de los grupos campaniformes de sus respectivas zonas y de áreas limítrofes, lo que no necesariamente hay que atribuir a factores cronológicos. De todos modos, el grupo de Wessex habrá coexistido con los estilos tardíos del campaniforme británico $^{48}$. Por el contrario, en la Bretaña falta el campaniforme tardío, y aunque hay indicios que el campaniforme del estilo internacional allí duró más tiempo que en otras zonas, no parece haberse producido un solapamiento temporal con las tumbas suntuarias del Bronce Inicial ${ }^{49}$. Debido a las razones expuestas más arriba, resulta bastante difícil determinar con seguridad la relación cronológica exacta entre el campaniforme y el grupo Vilavella-Atios.

También hay que tener en cuenta, que tanto en el caso de las tumbas suntuarias de Wessex y de la Bretaña, como en el del circulo de ritos funerarios Vilavella-Atios, se trata de las sepulturas de una élite social, que sólo representan una pequeña parte de la sociedad. La gran mayoría de túmulos o cistas sin ajuar, o con ajuares muy pobres ha contado con mucho menos interés por parte de la investigación, por presentar menos puntos de partida para un análisis arqueológico pormenorizado. Pero ello no impide constatar relaciones más o menos estrechas con otras regiones atlánticas.

Las pequeñas agrupaciones de cistas del Noroeste peninsular ${ }^{50}$, por ejemplo, comparten muchos rasgos estructurales con las necrópolis contemporáneas de Irlanda $^{51}$, pero también del oeste de Escocia ${ }^{52}$. Más alla de la topografía de los yacimientos y de detalles constructivos de las cistas en general, los elementos comunes incluyen la decoración interior de algunas de ellas (fig. 5). Lamentablemente desconocemos si las cistas decoradas de Pedra Marrada (Carnota, La Coruña) $^{53}$ y As Antas (Rodeiro, Pontevedra) $)^{54}$ estaban equipadas con ajuares de la facies Atios. De todos modos, y no obstante las diferencias en los detalles de la decoración, la cista de Kilmichael Glassary (Argyll) ofrece los mejores paralelos a las cistas decoradas de Galicia ${ }^{55}$.

Bajo el aspecto de su relación con otras áreas atlánticas, también hay que tener en cuenta la composición y la tipología de los ajuares del grupo Vilavella-Atios. Una de las diferencias que más destaca en relación a las tumbas de guerrero de Wessex y de la Bretaña, pero también a los grupos 'Food Vessel' irlandeses y escoceses, es la practica ausencia en el grupo Vilavella-Atios de puñales de remaches. De todos modos, la falta de puñales de remaches entre los ajuares del grupo Vilavella-Atios, a favor de los puñales de lengüeta, no debe ser entendido en un sentido exclusivamente cronológico.

Más bien, en comparación con los tipos habitualmente conocidos de contextos campaniformes, buena parte de los puñales de lengüeta procedentes de otros contextos del Occidente peninsular muestran rasgos tan evolucionados, y a veces tan estrechamente relacionados con los puñales bretones del tipo Rúmedon, que resulta difícil defender una cro-
48 Gerloff 1975, 47 s. 56. 61-63.

49 Harrison 1980, 111-113.

50 Para Portugal la necrópolis de Chã de Arefe (Durrães, conc. Barcelos, Minho), véase Silva / Lopes / Maciel 1981; para Galicia las necrópoles de Gandón (Cangas de Morrazo, Pontevedra), véase Peña Santos 1985, y Agro de Nogueira (Toques, La Coruña), véase Meijide Cameselle 1995.

\footnotetext{
51 Mount 1995, 97-112.

52 Dunwell / Neighbour / Cowie 1995, 279-288.

53 Vázquez Varela 1980 b, 42 s.

54 idem 1985/86, 91-95.

55 Clarke / Cowie / Foxton 1985, 286 s.
} 

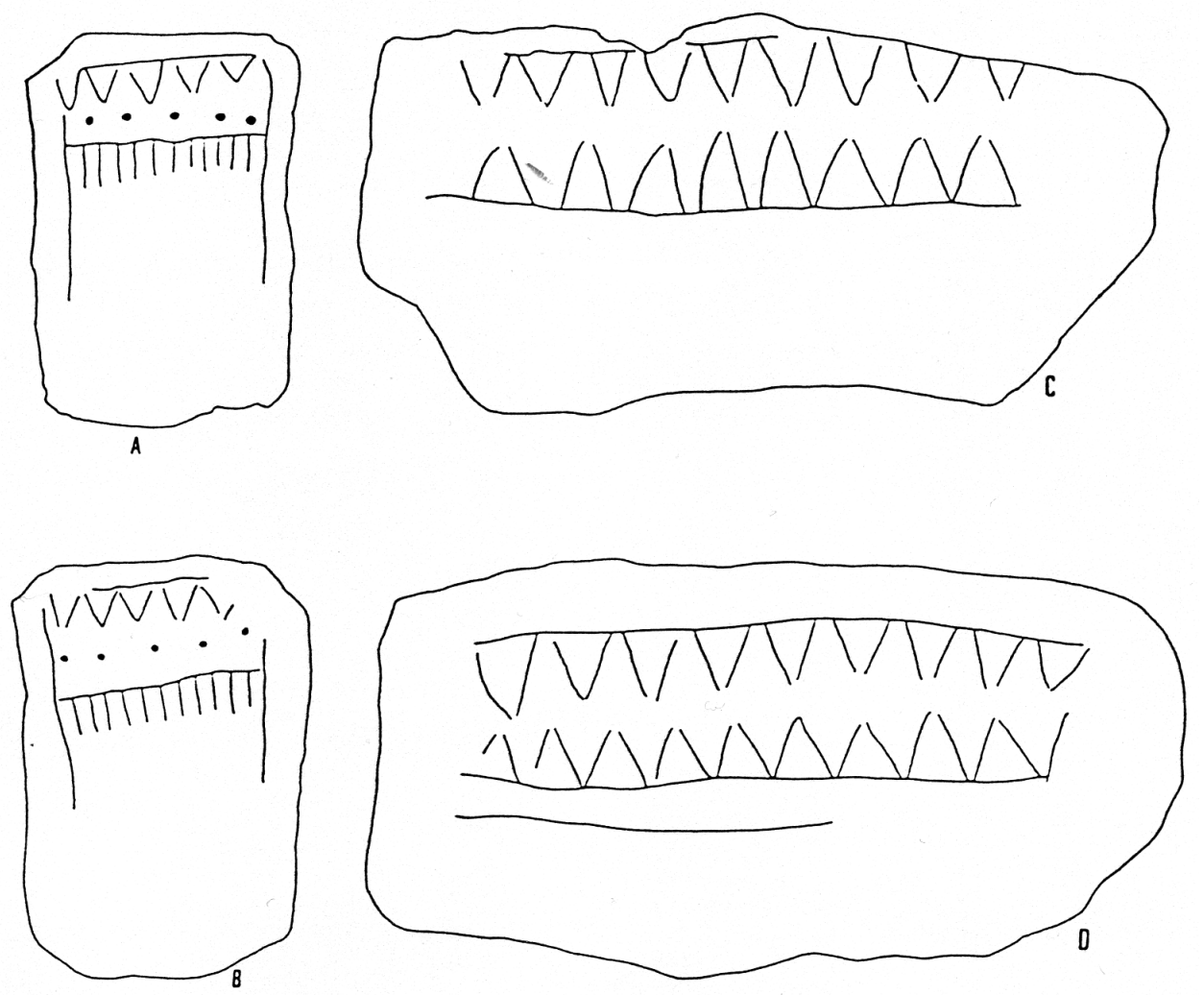

Fig 5. Lajas decoradas de la cista de A Insua (Cabana, La Coruña), según Vásquez Varela 1980, fig 6. Esc 1:3,5

nología más alta de los ejemplares peninsulares ${ }^{56}$. En el caso de un puñal de lengüeta, procedente del Pinhal dos Melos, en Fornos de Algodres (conc. Fornos de Algodres, Beira Alta), la base de la hoja aparentemente fue modificada, quitando los agujeros de remaches que en un origen llevaba y alargando la lengüeta. Sin estas modificaciones posteriores la pieza se incorporaría sin más en el tipo Rúmedon, aunque ciertos detalles nos hacen pensar que no se trata de una importación de la Bretaña, sino de una copia local de una pieza bretona ${ }^{57}$. Aparentemente, el uso continuado del enmangue de lengüeta y la escasez de puñales de remaches en el Bronce Inicial del Noroeste peninsular, se debe a una posición conservadora de los talleres locales, y no a un desconocimiento de la técnica de remaches. Sólo con el paso al Bronce Medio, la introducción de elementos del horizonte Tréboul-Saint-Brandan en el sector noroccidental de la Península Ibérica lleva a una acepta-

56 Así por ejemplo las piezas de Portomouro (Boiro, La Coruña), véase Almagro Gorbea 1973, 70-72 fig. 1, y de la Quinta da Romeira (São Vicente do Paúl, conc. Santarém, Ribatejo), véase Jalhay 1934, 22-30 fig. 1.

57 Paço / Ferreira 1957, 5-12 fig. 3; 4, 1; Brandherm 2003, 138 $\mathrm{n}^{\circ} .267$.

58 Brandherm 2001 a, 53-58.

59 Gachina 1997, 22-31; Gerloff 1975, 28 lám. 41 A, 4. ción generalizada del enmangue por remaches ${ }^{58}$.

También en relación a la composición de los elementos guerreros en los ajuares del grupo VilavellaAtios se observan diferencias con respecto a las tumbas de guerreros bretones. Aunque la distribución de las puntas Palmela, como forma característica del Bronce Inicial peninsular, se extiende por el Oeste de Francia hasta la Bretaña y incluso hasta el Suroeste de Inglaterra, allí estas armas ya no constituyen un elemento regular de los ricos ajuares masculinos $^{59}$. A su vez, en las tumbas suntuarias de la Bretaña muchas veces se encuentra un número elevado de puñales, rasgo que en los ajuares del grupo Vilavella-Atios no cuenta con paralelos ${ }^{60}$.

Conjuntos de armas semejantes existen de todos modos en el arte rupestre del Noroeste peninsular, siempre teniendo en cuenta el problema de identificar conjuntos 'cerrados' entre los grabados, o sea,

60 Posiblemente algunas de la tumbas bretonas que han proporcionado un número elevado de puñales -hasta un máximo de once piezas- fueron reutilizadas varias veces, acumulandose así elementos de distintos ajuares que en realidad pertenecen a toda una serie de enterramientos sucesivos (Needham 2000 a, 168-176). Aun así, el carácter de conjunto cerrado de algunos ajuares bretones con más de dos puñales parece fuera de cuestión (Gallay 1981, 110). 
grupos de representaciones que pertenecen a un mismo momento, y que corresponden a una combinación intencional de elementos iconográficos ${ }^{61}$. Seguramente se debe entender como un indicio en este sentido la representación de pares de armas blancas con dimensiones muy desiguales, que permitirían una diferenciación funcional en el sentido de una combinación puñal-espada corta. En el arte rupestre galaico-portugués se conocen varias incidencias de tal combinación, que en el registro arqueológico real queda mejor representado por el ajuar de la cista de $\operatorname{Atios}^{62}$. Por otra parte, la frecuente asociación de alabardas a los puñales o espadas cortas en el arte rupestre, constituye un importante argumento en contra de una simple equiparación de los conjuntos grabados con ajuares funera- rios simbólicos (fig. 6) ${ }^{63}$.

Como ocurre también en casi toda la fachada atlántica, en el sector noroccidental de la Península Ibérica las alabardas se hallan principalmente como objetos aislados o como parte de depósitos, pero nunca como elementos de ajuares funerarios. En consecuencia, el mejor paralelo a los conjuntos de armas del arte rupestre, no se encuentra entre los ajuares del grupo Vilavella-Atios, sino en el probable depósito de Monte Lioira (Rianjo, La Coruña) ${ }^{64}$. Este hallazgo, que a pesar de la tipología arcaica de las piezas, según las huellas de enmangue en algunos de los puñales sólo parece haber sido depositado en los inicios del Bronce Medio, confirma una vez más la coexistencia en un mismo momento cronológico del enmangue por lengüeta y del enman-

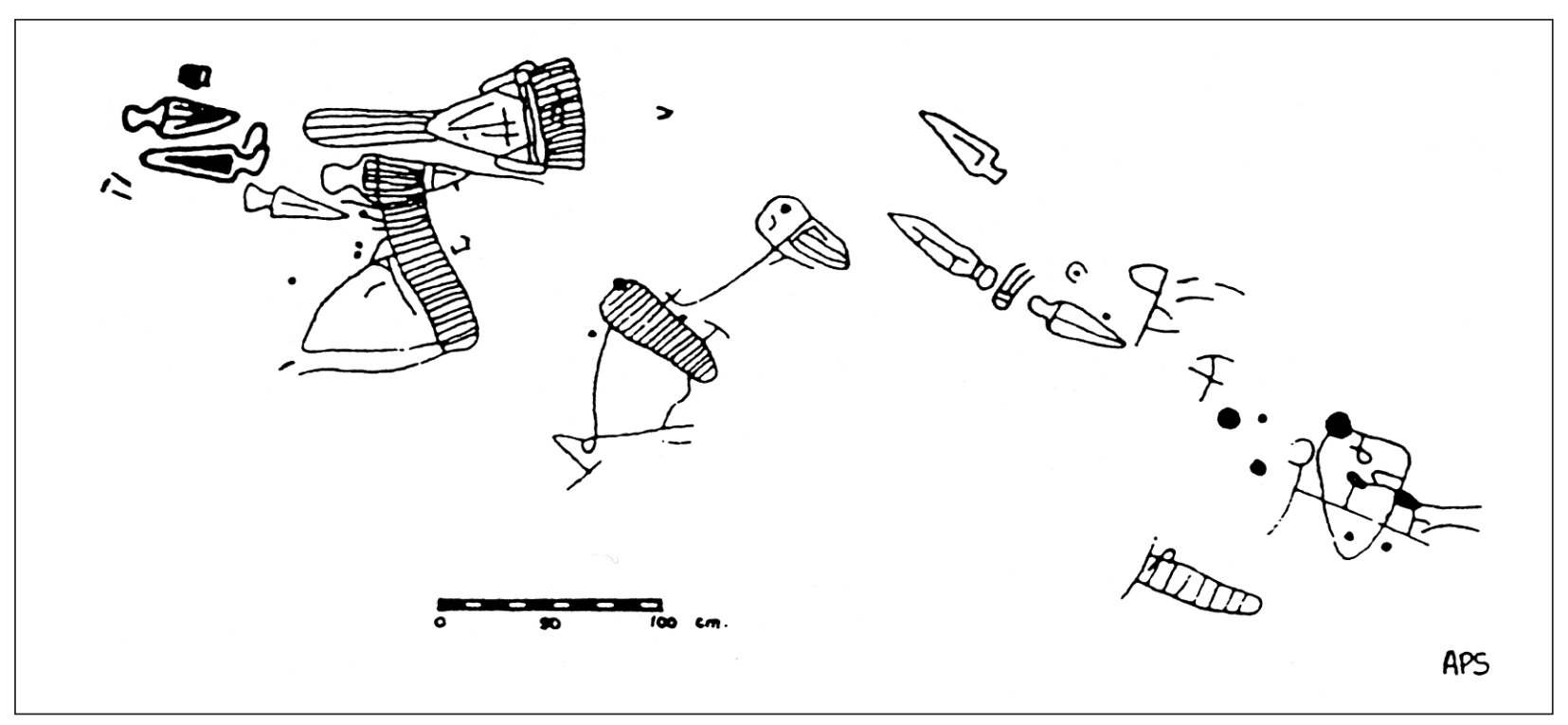

Fig 6. Conjunto de arte rupestre de O Castriño de Conxo (Santiago de Compostela, La Coruña), según Peña Santos 1980, fig. 3

61 Peña Santos 1980, 51-55; Comendador Rey 1997, 115-126.

62 Por ejemplo en los siguientes conjuntos de arte rupestre: Auga da Laxe III (Gondomar, Pontevedra), véase Costas Goberna / Fernández Pintos / Goberna Pena / Fernández Díaz 1984, 54. 202 lám. G14, 2. - Matabois I (Campo Lameiro, Pontevedra), véase García Alén / Peña Santos 1980, 30 fig. 20; 162, 25. 27. - Mogüelos (Cangas de Morrazo, Pontevedra), véase ibidem 36 s. fig. 32; 162, 1. 16. - Monte da Lage (Gandra, conc. Valença, Minho), véase Silva / Cunha 1986, 150 s. fig. 8. 13. - Monte da Pena (Rianjo, La Coruña), véase Calo Lourido / González Reboredo 1980, 208-210 fig. 3 fot. 4. - Pedra Ancha (Dumbria, La Coruña), véase Costas Goberna / Novoa Álvarez / Albo Morán 1993/94, 246. 249 fig. p. 253. 254. 259. Pedra das Ferraduras (Cotobade, Pontevedra), véase García Alén / Peña Santos 1980, 55 fig. 61; 162, 6. 15. - Primadorno I (Silleda, Pontevedra), véase ibidem 111 s. fig. 122; 162, 3. 8.

63 Por ejemplo en los siguientes conjuntos de arte rupestre: Auga da Laxe I (Gondomar, Pontevedra), véase Costas
Goberna / Fernández Pintos / Goberna Pena / Fernández Díaz 1984; 52.203 s. fig. p. 213 lám. G13. - Auga da Laxe III (Gondomar, Pontevedra), véase García Alén / Peña Santos 1980; fig. 162, 1. 2. 14. - Montecelo (Poyo, Pontevedra), véase García Martínez 1973, 118. - Monte da Pena (Rianjo, La Coruña), véase Calo Lourido / González Reboredo 1980, 208-210 fig. 3 fot. 2. 3. - Pedra Ancha (Dumbria, La Coruña), véase Costas Goberna / Novoa Álvarez / Albo Morán 1993/94, 246. 248 s. fig. p. 254. 259. - Poza de Lagoa II (Redondela, Pontevedra), véase García Alén / Peña Santos 1980, 109 fig. 163, 4. 5. 6. - Primadorno I (Silleda, Pontevedra), véase ibidem 111 s. fig. 122; 163, 12. 13.

64 Calo Lourido / Sierra Rodríguez 1974, 18 s. En la bibliografía posterior, este hallazgo frecuentemente se ha publicado bajo el topónimo de 'Leiro'. Como las piezas proceden de tierra removida, el carácter del hallazgo como depósito no se puede confirmar con certeza absoluta. 


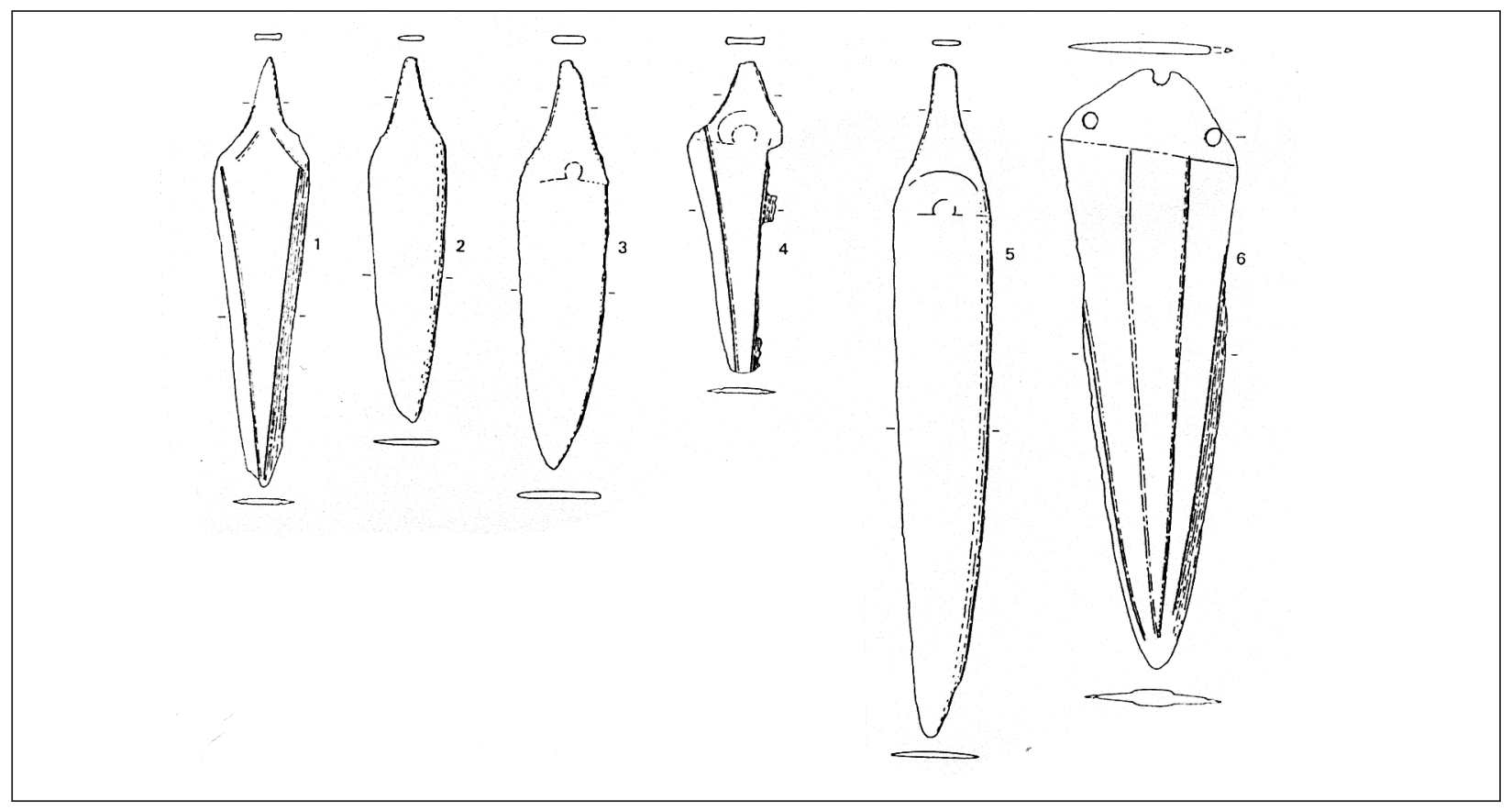

Fig 7. Deposito de Monte Lioira (Rianjo, La Coruña) Esc. 1:4

gue por remaches (fig. 7). De todas maneras y como regla general, en los depósitos del Noroeste peninsular las alabardas no se asocian a puñales, aunque sí constituyen depósitos, muchas veces en lugares relacionados con cursos de agua o humedales. La relación de los depósitos de alabardas con el agua es un rasgo común del Bronce Inicial en la fachada atlántica, característico también de los hallazgos franceses y británicos. Por el contrario, en el resto de la Península Ibérica, las alabardas o bien aparecen como elemento de depósitos que no mantienen ninguna relación con el agua, o bien como elemento de ajuares funerarios ${ }^{65}$. En este contexto no se debe olvidar que en los mapas de distribución geográfica de las alabardas, lo que observamos es la distribución de determinados ritos de deposición, lo que no coincide necesariamente con la distribución original de los tipos respectivos ${ }^{66}$. Así, la aparente concentración de alabardas del tipo Carrapatas en Trás-os-Montes en realidad es el resultado de un determinado rito de deposición, conociendose el tipo Carrapatas también en otras áreas de la

65 Brandherm 2003, 391-399.

66 ibidem lám. 161.

67 Concretamente se trata de los siguientes depósitos: Finca de la Paloma (Pantoja, Toledo), véase Harrison 1974 b, 58. 68 fig. 2. - Las Naves (Alloza, Teruel), véase Fernández / Beltrán 1951, 139 s. 'Valle del Manzanares' (Madrid), véase las Cortina 1981, 157-166. Para el fenómeno de la deposición selectiva en general véanse Needham 1988, 229-246; Brandherm en prensa.
Península Ibérica, donde suele aparecer en depósitos de composición mucho más heterogénea que los conjuntos monotípicos del Norte de Portugal ${ }^{67}$.

Otra categoría importante de objetos que ilumina las estrechas relaciones entre las distintas regiones de la fachada atlántica durante el Bronce Inicial son los productos de la orfebrería, siendo los collares del tipo São Bento con su distribución entre el Tajo y la Bretaña uno de los ejemplos más destacados ${ }^{68}$. Rasgos comunes de la orfebrería atlántica también se detectan en los guarniciones procedentes de las sepulturas de la Quinta da Agua Branca (fig. 2 A, 2. 3) y de Atios (fig. 2 B, 4. 5). Los paralelos más próximos para estos guarniciones se conocen como elementos de un ajuar 'Food Vessel' irlandés de Topped Mountain (co. Fermanagh) así como de los ajuares escoceses de Blackwaterfoot (Buteshire), Collessie (Fife), Comuston Cross (Angus) y Skateraw (East Lothian $)^{69}$. Una pieza del túmulo 7 del Dorset Ridgeway en Wessex, por el contrario, se distingue por la chapa de pomo cerrada y por el estilo de su manufactura de los ejemplares mencionados antes ${ }^{70}$. Un estrecho paralelo a los ejemplares británicos

68 Blas Cortina 1994, 112-116 fig. 7.

69 Para el hallazgo de Topped Mountain véase Harbison 1988, 106 fig. 62; para los hallazgos escoceses véase Coles 1968/69, 91 s. fig. 35, 2. 3; 36, 1; 37, 1.2.

70 Clarke / Cowie / Foxton 1985, fig. 4, 59. Para la diferenciación de esta pieza como producto de la orfebrería de Wessex frente a los ejemplares escoceses y irlandeses véase también Needham 2000 b, 52-54. 
también se encuentra en una chapa de guarnición del depósito de Abía de la Obispalía (Cuenca), demostrando la penetración de elementos atlánticos hasta el interior de la Península ${ }^{71}$.

Otro producto de la orfebrería que puede servir como indicador del contacto con otras áreas de la fachada atlántica, es el brazal de arquero de oro procedente de Vila Nova de Cerveira, claramente relacionado con los brazales decorados por remaches de oro de Barnack (Cambridgeshire), Driffield (Yorkshire) oder Culduthel (Inverness-shire), como ya indicó J. J. Taylor ${ }^{72}$.

En este contexto tampoco hay que olvidar los espirales de cobre, plata y oro de la sepultura de Carnoët, cerca de Quimperlé (dép. Finisterre) ${ }^{73}$, estrechamente relacionados con los espirales de oro del tipo Vale Viegas. A pesar de que la distribución geográfica principal de estos se encuentra en el Alemtejo y en la Extremadura, varios ejemplares también proceden del Noroeste peninsular ${ }^{74}$.

En Irlanda, la orfebrería típica del grupo Vilavella-Atios queda representada por un diadema sin procedencia exacta del condado Cavan, así como por un pendiente de Dacomet (co. Down), cuyo análisis indica que se trata de una importación procedente de la Península Ibérica ${ }^{75}$. La copia de una lúnula irlandesa de Cabeceiras de Basto (conc. Braga, Minho) con casi toda probabilidad fue manufacturado localmente por sus rasgos estilísticos ${ }^{76}$. De todas maneras, el número reducido de los elementos de orfebrería y el hecho de que muchos de los objetos no se pueden relacionar con otras categorías de artefactos, dificulta tanto conclusiones acerca de su cronología exacta, como acerca de la organización de los contactos entre las distintas regiones.

Otro problema que se presenta en relación con el circulo de ritos funerarios Vilavella-Atios, es la delimitación de este grupo frente a fenómenos coetáne-

71 Pingel 1992, 243 nº.1 80 lám. 20, 11.

72 Taylor 1978, 244. Se ha insinuado que esta pieza pudiera haber formado parte del ajuar de la cista de Agua Branca (Harrison 1980, 139), pero según la documentación disponible sobre este hallazgo, esta hipótesis se puede excluir con casi toda seguridad (Fortes 1906 a, 241-252). Efectivamente, en lo que se refiere a este excepcional brazal de arquero de oro, se desconocen tanto el lugar exacto como las circunstancias del hallazgo. El expediente del museo menciona como única indicación de la procedencia 'Vila Nova de Cerveira'. Parece además muy probable la pertenencia al mismo ajuar de una espiral de oro, que con la misma procedencia se adquirió junto con el brazal, sin que hubiera prueba definitiva de tal asociación (Spindler 1993, 56-62). Para los paralelos británicos véase también Clarke / Cowie / Foxton 1985, fig. 4,$15 ; 4$, 16. Una pieza similar a los británicos, pero con os en regiones limítrofes al sur del Duero y en la Meseta. De las Beiras portuguesas se conoce un número importante de túmulos con características constructivas muy parecidas a las que presentan los monumentos de la facies Vilavella. De todos modos, los túmulos al sur del Duero, con la rara excepción de algunos fragmentos de cerámica gruesa, en ningún caso contienen ajuares ${ }^{77}$.

Al igual que en el Noroeste, al sur del Duero también hay indicios para un uso continuado o una reutilización de tumbas megalíticas durante la Edad del Bronce $^{78}$. Por otro lado, cistas como las de la facies Atios son desconocidas en las Beiras, y al sur del río Vouga incluso los túmulos no megalíticos se hacen cada vez menos frecuentes. Puñales de lengüeta, que por su tipología se relacionan con los ajuares del grupo Vilavella-Atios, en esta zona sólo se conocen como hallazgos aislados, aparentemente depositados como piezas individuales ${ }^{79}$.

La sepultura de Pera Gorda, situada al sur de esta zona de transición, en la feligresía de Montelavar, y epónima para el respectivo horizonte cronológico y grupo cultural según la definición de Harrison, en este contexto merece una particular atención. Por su construcción como cista, que con las reservas debidas a la deficiente documentación del hallazgo, corresponde a las convenciones del circulo de ritos funerarios Vilavella-Atios, se distingue radicalmente de la arquitectura funeraria habitual de la zona. También el ajuar sin más permitiría una atribución al grupo Vilavella-Atios, aunque bajo aspectos tipológicos los elementos del ajuar - el puñal de lengüeta en particular- no se corresponden a piezas corrientes en el Noroeste ${ }^{80}$. Faltan pues los indicios decisivos para una interpretación de la sepultura de Pera Gorda como la inhumación de un extranjero, procedente del Norte de Portugal o de Galicia. De todos modos, no se puede excluir con total seguri-

remaches de plata en vez de oro, procede de la Motilla de El Acequión (Albacete), lo que constituye otro indicio para la penetración de elementos atlánticos hasta el interior de la Península Ibérica (Martín Morales / Fernández Miranda / Fernández-Posse / Gilman 1993, fig. 12 b).

73 Briard / Mohen 1974, 51 s. fig. 4, 1-3; 6, 1. 2.

74 Pingel 1992, 53.

75 Taylor 1978, 233-235.

76 ibidem 231.

77 Kalb / Höck 1979, 43-56; Silva 1997, 608-616.

78 ibidem 616.

79 Jalhay 1934; Paço / Ferreira 1957, 5-12.

80 Brandherm 2003, 125 n .209. 
dad tal interpretación, ya que el atípico puñal de este ajuar tampoco cuenta con buenos paralelos en la zona $^{81}$.

Con más frecuencia que en la región al sur del Duero aparecen ajuares relacionados con el grupo Vilavella-Atios tanto en la Submeseta Norte como en Asturias y Cantabria. Destaca en este contexto el ajuar de El Vado (Celada de Roblecedo, Palencia), con su combinación de puñal de lengüeta y dos puntas Palmela, sin elementos cerámicos ${ }^{82}$. No obstante, la inhumación en una grieta constituye una clara rotura en relación a los característicos ritos funerarios del grupo Vilavella-Atios.

También las sepulturas de Los Pasos (Zamora) ${ }^{83}$, Los Palomares (Villalmanzo, Burgos) ${ }^{84}$, Valdeprados (Aldea del Rey Niño, Ávila) ${ }^{85}$ como de El Teriñuelo (Aldeavieja de Tormes, Salamanca) ${ }^{86}$ presentan ajuares que contienen tanto puñales de lengüeta y/o puntas Palmela como cerámica lisa. En la construcción de las tumbas, por cierto, las mencionadas sepulturas presentan diferencias importantes en relación al grupo Vilavella-Atios. En el caso de las sepulturas de Los Pasos y Valdeprados se trata de fosas simples, características también del rito funerario del campaniforme en la Submeseta Norte. En Los Palomares encontramos una de las pocas sepulturas en pithos de la zona forma de sepultura totalmente desconocida en el Noroeste. Finalmente, en el caso de El Teriñuelo se trata de una inhumación posterior en la cámara de un monumento megalítico mucho más antiguo.

También aparecen cistas aisladas o en pequeños grupos en la Submeseta Norte, siempre sin ajuar, sobretodo en su margen occidental, donde su presencia probablemente se debe a la influencia atlánti$\mathrm{Ca}^{87}$. De la Submeseta Norte igualmente se conocen inhumaciones del Bronce Inicial bajo túmulo, sea con o sin cerámica campaniforme, pero en este último caso nunca asociado a un ajuar metálico. Aquí, en la mayoría de los casos, y al igual que en el Noroeste, se trata de excavaciones antiguas con documentación inadecuada, lo que limita las posibilidades de identificar paralelos entre los dos grupos.

81 Para el concepto del 'extranjero' en el registro arqueológico véase Wels-Weyrauch 1989, 162-168. Las posibilidades para identificar personas 'extranjeras', particularmente mujeres, son bastante mejores en la Edad del Bronce de Centroeuropa, donde los elaborados adornos y otros elementos indumentarios de bronce, muchas veces muestran una fuerte diferenciación regional (Jockenhövel 1991, 49-51).

82 Delibes de Castro / Fernández Miranda 1981, 153-155 fig. 2 lám. 2. De todas maneras, debido a las circunstancias del hallazgo, no es de descartar por completo la posibilidad de que en un origen hubiera existido también un ajuar cerámico,
De todos modos, donde hay excavaciones modernas en monumentos tumulares de la Meseta, no siempre se trata de inhumaciones individuales, sino a veces dobles o en algún caso incluso múltiples, por tanto de un rito funerario que hasta el momento no se ha documentado para el grupo Vilavella-Atios ${ }^{88}$. En teoría, esta aparente diferencia en buena medida pudiera haberse producido como consecuencia de la mejor conservación del hueso en las tumbas de la Meseta. Muchas de las cistas y otros monumentos funerarios del Noroeste también pudieran haber acogido restos de varios individuos, sobretodo si se toma en cuenta la posibilidad de inhumaciones parciales o secundarias, que en la Meseta se han podido observar en varias ocasiones ${ }^{89}$. De todas maneras, no hay indicios en los ajuares del grupo VilavellaAtios que corroboraren tal hipótesis.

Además, en cuanto a los ajuares metálicos del Bronce Inicial de la Meseta hay que hacer constar que bajo aspectos tipológicos sus elementos se distinguen bastante de los objetos hallados en contextos del grupo Vilavella-Atios. Esto no sólo se refiere a los adornos y a los puñales de lengüeta, sino también a las puntas Palmela, entre las cuales en el Noroeste dominan ejemplares con hoja asimétrica, prácticamente desconocidas en la Meseta, a pesar del mayor número de hallazgos procedentes de allí.

También para el ajuar cerámico hay que hacer constar importantes diferencias tipológicas entre las sepulturas de la Meseta por un lado y del Noroeste por otro. Si la cerámica de las sepulturas del grupo Vilavella-Atios tiene poco que ver con el campaniforme, los ajuares cerámicos de la sepulturas referidas del Bronce Inicial de la Meseta principalmente se componen de formas lisas del campaniforme: un vaso campaniforme en Los Pasos y Valdeprados respectivamente, un cuenco en Los Palomares y un juego completo de recipientes 'Ciempozuelos liso' en El Teriñuelo, sin que en este último caso, debido a las circunstancias del hallazgo, la pertenencia de todos los vasos a un mismo ajuar quede fuera de duda.

Para una delimitación exacta de los distintos círculos de ritos funerarios del Bronce Inicial, que for-

que fuese victima de la explosión con que se abrió la grieta.

83 Maluquer de Motes 1960, 119 s.

84 Delibes de Castro 1971, 410 fig. 3 lám. 2.

85 Fabián García 1992, 127.

86 Morán Bardón 1930, 57 lám. 18.

87 Gallay 1970, 75-90; González Alcalde / García NavajoUbierna 1996, 31-35.

88 Rojo Guerra 1989, 108-113; Fabián García 1992, 106-108; Garrido Pena / Rojo Guerra / García Martínez de Lagrán 2005, 414-416.

89 ibidem. 
man parte del registro arqueológico en la mitad norte de la Península Ibérica, es entonces necesario diferenciar tanto según los propios ritos funerarios como según la tipología de los elementos del ajuar metálico y de la cerámica. Clasificar ajuares con formas lisas del repertorio campaniforme junto con ajuares sin cerámica o ajuares con cerámica de otras tradiciones culturales frente a los típicos ajuares campaniformes como un único conjunto cronológico o cultural -así como lo implica el concepto de un 'horizonte' o 'grupo' Montelavar-seguramente inducía a error ${ }^{90}$.

Para una mejor diferenciación terminológica de los enterramientos con cerámica campaniforme lisa frente a las sepulturas del campaniforme del estilo Ciempozuelos tanto como a las tumbas del grupo Vilavella-Atios, queremos proponer el término de la 'facies Los Pasos'. En el caso del hallazgo epónimo se trata de un conjunto cerrado, que tanto en su ajuar cerámico como en la forma del enterramiento indica las estrechas relaciones de esta facies con las típicas sepulturas del grupo Ciempozuelos. Esta diferenciación terminológica, de todos modos, no quiere decir que en las zonas fronterizas entre las áreas de mayor dispersión geográfica de los respectivos fenómenos no se dieron mezclas entre sus distintos elementos. $\mathrm{Al}$ igual que el ajuar del túmulo 1 de Chã de Carvalhal introduce elementos del grupo Palmela en un contexto propio del grupo Vilavella-Atios, el hallazgo de Cañada Rosal presenta una mezcla entre elementos de la facies Los Pasos y el grupo Ciempozuelos ${ }^{91}$, tratandose en ambos casos de excepciones a la regla general que establece el rito funerario de los respectivos grupos. Salvo estos dos enterramientos, sólo la combinación de un vaso campaniforme liso con un cuenco decorado del estilo Ciempozuelos en el enterramiento 2 de Valhondo (Pajares de Adaja, Ávila) ${ }^{92}$ se pude mencionar como caso de mezcla de elementos de la facies Los Pasos con el grupo Ciempozuelos.

Mucho más común aparece la combinación de vasos campaniformes decorados con otras formas de cerámica lisa, la llamada 'Begleitkeramik', en la Submeseta Norte por ejemplo en el túmulo 1 de Aldeagordillo (Ávila) ${ }^{93}$ o en el enterramiento de Los Retajones (Villaverde de Iscar, Segovia) ${ }^{94}$. Estos ajuares no se incluyen en la definición de la facies Los Pasos.

Además, el hallazgo de Cañada Rosal llama la atención sobre las dificultades a la hora de diferen- ciar la facies Los Pasos de los enterramientos del horizonte Ferradeira en el Suroeste peninsular. Son otra vez las diferencias tipológicas entre los elementos del ajuar metálico de los dos grupos y la construcción de las sepulturas, los que en la gran mayoría de los casos ofrecen un criterio inequívoco, por ejemplo la inhumación en cista o bajo lajas, en este último caso siempre en posición extendida, que fuera del Suroeste no suelen aparecer en combinación con cerámica campaniforme lisa ${ }^{95}$. Al contrario de las zonas de dispersión del grupo Vilavella-Atios y de la facies Los Pasos, el Suroeste se distingue por una ausencia total del campaniforme decorado en contextos funerarios, así que no existen argumentos para defender una diferenciación cronológica entre el campaniforme de zonas limítrofes y los enterramientos del horizonte Ferradeira ${ }^{96}$. Estamos entonces ante una situación análoga a la del Noroeste, donde por el momento tampoco disponemos de criterios fiables para establecer una sucesión cronológica entre el campaniforme por un lado, y las facies Vilavella y Atios por el otro.

A modo de resumen se puede destacar que el concepto de un grupo u horizonte 'Montelavar' resulta erróneo, mezclando elementos de varios fenómenos distintos a nivel peninsular. La gran mayoría de los hallazgos que caen bajo la definición propuesta por Harrison, efectivamente se concentran en el sector noroccidental de la Península Ibérica, delimitando de una manera bastante concreta un determinado circulo de ritos funerarios, que aquí hemos subsumido bajo el termino del grupo Vilavella-Atios.

Con este fenómeno, el Noroeste peninsular se encuadra bastante bien en el Bronce Inicial y Medio de la fachada atlántica, que se caracteriza por círculos de ritos funerarios fuertemente regionalizados, con una arquitectura sepulcral altamente diferenciada que incluye construcciones tumulares tanto como cistas, por lo menos en aquellas áreas donde el subsuelo geológico ofrece los requisitos indispensables. Frente a otras regiones de la fachada atlántica, donde los ajuares funerarios frecuentemente incluyen cerámica de tradición campaniforme, los círculos de ritos funerarios de Wessex, de la Bretaña y del Noroeste peninsular destacan por la abundancia de armas y metales preciosos tanto como por la escasez de cerámica en los ajuares.

Aunque hemos insistido en subrayar la importancia del Noroeste peninsular como una de las

\footnotetext{
90 Prieto Martínez 1999, 85-87.

91 Harrison 1974 a, 84-90.

92 Martín Valls / Delibes de Castro 1989, 62-64.

93 Fabián García 1992, 106-110.
}

\author{
94 Delibes de Castro 1979, 5-18. \\ 95 Schubart 1975, 121 \\ 96 ibidem 121-128.
}


regiones principales dentro de la red de interacciones que caracterizan la fachada atlántica sobretodo durante el Bronce Inicial, no se debe olvidar nunca la dimensión diacrónica de estas mismas interacciones. Así, el cambio fundamental con que se inicia el Bronce Final en la fachada atlántica se hace notar en primer lugar en el registro arqueológico con la casi total desaparición de los enterramientos y un correspondiente aumento en la cantidad de los depósitos, hecho que por si mismo no permite sacar conclusiones sobre los procesos históricos que lo condicionan. Tampoco en este contexto se debe olvidar que las estrechas relaciones del Noroeste peninsular con otras regiones de la fachada atlántica no se inician con la Edad del Bronce, pero que ya con anterioridad la misma red de comunicación se encontraba en pleno funcionamiento, como lo atestigua el fenómeno del megalitísmo atlántico para el Neolítico ${ }^{97}$, y el horizonte de las primeras tumbas individuales para el Calcolítico, en un momento inmediatamente anterior a la formación del grupo Vilavella-Atios ${ }^{98}$.

\section{Apéndice}

Facies Vilavella

1. Boel, Outes, La Coruña. - Mamoa, detalles de la construcción tumular desconocidos; como ajuar se mencionan dos puñales de lengüeta o de remaches -la información en este respecto resulta contradictoria-, hoy desaparecidos. López Cuevillas / Bouza Brey 1929, 52; López Cuevillas 1955, 10; idem 1956, 300.

2. Chã de Carvalhal (túmulo 1), Grilo, conc. Baião, Douro Litoral. - Mamoa con cámara y revestimiento de piedras; de la cámara sólo procede un cuenco del estilo Palmela; dos puñales de lengüeta y cinco puntas Palmela se encontraron en dos puntos distintos fuera de la cámara; de la tierra del túmulo proceden dos bolas petreas tanto como fragmentos de cerámica lisa y campaniforme decorada; materiales conservados en el Museo Municipal de Baião Cruz 1992.

3. Monte das Cabras, Lalín, Pontevedra. Mamoa sin elementos constructivos de piedra; como ajuar se recuperaron un puñal de lengüeta y tres puntas Palmela (fig. $1 \mathrm{~A}$ ); materiales

97 Eogan 1990, 133-135.

98 Para el horizonte de las tumbas individuales calcolíticos en las Islas Británicas véase Clarke / Cowie / Foxton 1985, 63-67. conservados en el Museo de Pontevedra. López Cuevillas / Bouza Brey 1929, 52.

4. Monte de Penamá, Gomesende, Orense. Mamoa con construcción interior de piedras, no se conocen más detalles constructivos; como ajuar López Cuevillas sólo menciona un puñal de lengüeta, hoy desparecido. - López Cuevillas 1955, 11; idem 1956, 299 s.

5 a. Parxubeira (túmulo 2), Mazaricos, La Coruña. - Enterramiento posterior en una mamoa con revestimiento de piedras, cámara megalítica poligonal y corredor; de la cámara se recuperaron, aparte de los ajuares pertenecientes a los enterramientos originales de época neolítica, una punta Palmela y fragmentos de tres vasos campaniformes; otros dos fragmentos de cerámica campaniforme proceden del corredor, y uno de la propia mamoa en la parte trasera de la cámara, donde también se recuperó un vaso típico del Bronce Inicial; no obstante, la atribución de los distintos elementos a ajuares individuales parece imposible; materiales conservados en el Museo Histórico-Arqueológico de La Coruña. - Rodríguez Casal 1989, 30-38; 43-61.

5 b. Parxubeira (túmulo 4), Mazaricos, La Coruña. - Enterramiento posterior en una mamoa con revestimiento de piedras y cámara megalítica destruida; encima del revestimiento se recuperaron una punta Palmela y una lámina de sílex como único ajuar; materiales conservados en el Museo Histórico-Arqueológico de La Coruña. - Rodríguez Casal 1989, 40-42; 56.

6. Pena Coba, Melide, La Coruña. - Mamoa, los detalles de la construcción tumular se desconocen; como ajuar únicamente se menciona una "espada", hoy desaparecida. - Álvarez Carbadillo 1906, 199 nota 1; López Cuevillas / Bouza Brey 1929, 53; López Cuevillas 1955, 11.

7. Pera Gorda, Montelavar, conc. Sintra, Estremadura. - Construcción al modo de una cista, pero en la publicación original Nogueira / Zbyszewski hablan de un túmulo, aunque no queda muy claro en que indicios se apoyan; en las fotos que reproducen, de todas maneras no quedan restos visibles de una construcción tumular; como ajuar se documentaron un puñal

246-251; para los respectivos hallazgos peninsulares véase MacWhite 1951, 45; Fábregas Valcarce 1983, 31-33; Rodríguez Casal 1983, 9-11. 
de lengüeta y dos puntas Palmela, así como otro objeto de cobre o bronce, hoy desaparecido; las demás piezas se conservan en el Museu dos Serviços Geológicos de Lisboa. Nogueira / Zbyszewski 1943.

8. Vilar, Guilhabreu, conc. Vila do Conde, Douro Litoral. - Mamoa, se desconocen los detalles de la construcción tumular; como ajuar quedan documentado una punta Palmela y un brazal de arquero, conservados en el Museu Regional de Vila do Conde. - Jorge 1988, 89.

9. Vilavella (túmulo 240), Puentes de García Rodríguez, La Coruña. - Mamoa sin construcción interior de piedras; como ajuar se recuperaron una diadema de oro, un puñal de lengüeta y cuatro puntas Palmela (fig. 1 B); una de las puntas Palmela se conserva en el Museo Provincial de Prehistoria y Arqueología de Santander, los demás objetos en el decanato de la facultad de Historia y Geografía de la Universidad de Santiago de Compostela. Iglesia 1907, 62-64 fig. p. 63; López Cuevillas / Bouza Brey 1931, 60 fig. 20; Harrison 1974 a, 85 fig. 9 (una de las puntas Palmela que figura ahí no pertenece al ajuar).

\section{Facies Atios}

10. As Antas, Rodeiro, Pontevedra. - Cista, detalles de la construcción desconocidos; como ajuar se documentaron un pequeño puñal de lengüeta y un recipiente cerámico a fondo plano y con perfil en S; paradero de los hallazgos desconocido. - Monteagudo / García Alén / Lois Meijomil 1981, 135; Vázquez Varela 1985/86, 91-93; Rodríguez Casal 1989, 72.

11. Atios, Porriño, Pontevedra. - Cista grande; como ajuar se recuperaron dos puñales de lengüeta, dos guarniciones de chapa de oro y una espiral de plata, otra espiral de plata se desintegró en la excavación debido a su mal estado de conservación (fig. 2 B); un bloque de cuarcita, mencionado por los excavadores, erróneamente fue interpretado por Harrison (1974 b, 68) como yunque; el bloque se conserva con los demás materiales en el Museo Municipal "Quiñones de León" de Vigo; su forma irregular nunca hubiera permitido su uso como yunque metalúrgico, más bien se trata de una piedra-almohada en sentido literal, soportando la cabeza del muerto. - Álvarez Blázquez / Acuña Castroviejo / García Martínez 1970, 20-36; Harrison 1974 b, 52-57; 67 s. fig. 1; Pingel 1985, 37-39 fig. 5.

12. Chã de Arefe (cista 1), Durrães, conc.
Barcelos, Minho. - Cista colocada en el centro de un circulo de piedras; como ajuar se recuperaron una punta Palmela, un brazal de arquero y un vaso de cerámica lisa, de forma subcilíndrica; materiales conservados en el Museu Regional de Vila do Conde. - Silva / Lopes / Maciel 1981, 50-52; Jorge 1988, 89.

13. Pedra Marrada, Carnota, La Coruña. - Cista, detalles de la construcción desconocidos; como ajuar se han documentado un puñal de lengüeta y un brazal de arquero (fig. 2 C); materiales conservados en el Museo Histórico-Arqueológico de La Coruña. - Luengo Martínez 1964/65, 347; Ruiz-Gálvez Priego 1979, 153 fig. 1, 2; Vázquez Varela 1980 b, 42 s.

14. Quinta da Agua Branca, Lobelhe, conc. Vila Nova de Cerveira, Minho. - Cista grande; el ajuar se compone por un puñal de lengüeta, una diadema de oro, dos espirales y dos anillos de oro, que según su posición en la cista posiblemente habrá que interpretar como guarniciones de la empuñadura del puñal (fig. 2 A); materiales conservados en el Museu Nacional de Arqueologia de Lisboa. - Fortes 1906 a, 241-252; idem 1906 b, 157-178; López Cuevillas 1955, 6-8; Schubart 1975, 79.

15. Santa Comba, La Coruña. - Cista, detalles constructivos desconocidos; como ajuar sólo está documentado un puñal de lengüeta, conservado en el Museo Histórico-Arqueológico de La Coruña. - Ruiz-Gálvez Priego 1979, 153 fig. 1,1 .

16. São Bento, Balugães, conc. Barcelos, Minho. Construcción subterránea, posiblemente cista; se desconocen los detalles del hallazgo; como ajuar Estacio da Veiga menciona una gargantilla de tiras de oro y cuatro puntas Palmela, de las cuales una ya se había perdido en aquel momento sin más documentación; así no se puede descartar que en el caso de esta cuarta "punta de lanza" realmente se tratase de un puñal de lengüeta; se desconoce el paradero del collar, las tres restantes puntas se conservan en el Museu Nacional de Arqueologia de Lisboa. - Estacio da Veiga 1891, 46 s. lám. 4; Pingel 1992, 286 lám. 49, 2.

17. Tarayo, Malpica de Bergantiños, La Coruña.Cista, detalles de la construcción desconocidos; como ajuar se recuperaron un puñal de lengüeta, un "botón" de materia orgánica (posiblemente el pomo del puñal), una lasca de cuarcita y un vaso de cerámica de forma subcilíndrica; 
materiales conservados en el Museo HistóricoArqueológico de La Coruña. - Ruiz-Gálvez Priego 1979, 153 fig. 1, 5; Monteagudo / García Alén / Lois Meijomil 1981, 135 fig. 26.

\section{Bibliografía}

ALMAGRO GORBEA, M. (1973): "La espada de Santiago", Cuad. Estud. Gallegos, 28, 70-72.

ALMAGRO GORBEA, M. (1995): "Ireland and Spain in the Bronze Age", J. Waddell / E. Shee Twohig (eds.), Ireland in the Bronze Age. Proceedings of the Dublin Conference, April 1995, Dublin, 136-148.

ÁlVAREZ BLÁSQUEZ, J. M. / ACUÑA CASTROVIEJO, F. / GARCÍA MARTÍNEZ, M. C. (1970): "Cista y ajuar funerario de Atios (Porriño)", Cuad. Estud. Gallegos, 25, 20-36.

ÁlVAREZ CARBADILLO, E. (1906): "Protohistoria: ligera contribución al estudio de cobres y bronces de la región gallega, conocidos con el nombre de célticos", Bol. Real Acad. Gallega, 1, 197-202.

ALVES, F. M. (1934): Memórias arqueológico-históricas do distrito de Bragança IX, Oporto.

ALVES, F. M. (1938): Memórias arqueológico-históricas do distrito de Bragança X, Oporto.

ALVES, F. M. (1947): Memórias arqueológico-históricas do distrito de Bragança, XI, Oporto.

BETTENCOURT, A. M. S. (1997): “Expressões funerárias da Idade do Bronze no Noroeste peninsular", Actas del II Congreso de Arqueología Peninsular II: Neolítico, Calcolítico y Bronce, Zamora 1996, Zamora, 621-632.

BLAS CORTINA, M. A. de (1981): "Una alabarda procedente del valle del Manzanares (Madrid)", Zephyrus, 32/33, 157-166.

BLAS CORTINA, M. A. (1994): "El anillo áureo de tiras de la Mata'l Casare I y su localización megalítica", Madrider Mitt., 35, 107-122.

BOUZA BREY, F. (1927): “Aportazón ao estudio da prehistoria galega: Depósito inédito dos primeiros tempos do Bronce", Bol. Real Acad. Gallega, 16, 153-158.

BRANDHERM, D. (2001 a): "Gau-Bickelheim und der Westen, eine iberische Randnotiz", D. Büchner (ed.), Studien in memoriam Wilhelm Schüle, Internationale Archäologie, studia honoraria, 11, Rahden, 53-61.
BRANDHERM， D. (2001 b): “Die ältere Bronzezeit im hispanischen Nordwesten und ihre atlantischen Beziehungen", M. Blech / M. Koch / M. Kunst (eds.), Hispania Antiqua Denkmäler der Frühzeit, Maguncia, 193-204.

BRANDHERM, D. (2002): “Zur Kultur der älteren Bronzezeit im Nordwesten der Iberischen Halbinsel und ihren atlantischen Beziehungen", Madrider Mitt., 43, 22-60.

BRANDHERM, D. (2003): Die Dolche und Stabdolche der Steinkupfer- und der älteren Bronzezeit auf der Iberischen Halbinsel, PBF, VI, 12, Stuttgart.

BRANDHERM, D. (en pensa): "Sobre el origen del fenómeno de los depósitos en la Península Ibérica: ocultaciones de objetos metálicos de los inicios de la Edad del Bronce", G. Delibes de Castro / J. Fernández Manzano (eds.), El hallazgo leonés de Valdevimbre y los depósitos del Bronce Final atlántico en la Península Ibérica. Actas del coloquio "Guardar - resguardar aguardar”: arqueología de los depósitos metálicos del Bronce Final en la Península Ibérica. León 23 y 24 de noviembre de 2005.

BRIARD, J. (1984): Les tumulus d'Armorique, L'âge du Bronze en France, 3, Paris.

BRIARD, J. / LE GOFFIC, M. / ONNEE, Y. (1994): Les tumulus de l'âge du Bronze des Monts d'Arree, Rennes.

BRIARD, J. / MOHEN, J.-P. (1974): "Le tumulus de la forêt de Carnoët à Quimperlé (Finistère)", Ant. Nat., 6, 46-60.

CABRÉ AGUILÓ, J. (1915-20): "Espoli funerari, amb diadema d'or, d'una sepultura de la primera Edat del Bronze de Montilla (Córdova)", Anu. Inst. Estud. Catalans, 6, 539-546.

CALO LOURIDO, F. / GONZÁLEZ REBOREDO, X. M. (1980): "Estación de arte rupestre de Leiro (Rianxo - A Coruña)", Gallaecia, 6, 207-216.

CALO LOURIDO, F. / SIERRA RODRÍGUEZ, J. C. (1974): "Leiro, Santa Maria de", Gran Enciclopedia Gallega XIX, Santiago - Gijón, $18 \mathrm{~s}$.

CLARKE, D. V. / COWIE, T. G. / FOXTON, A. (eds.), (1985): Symbols of Power at the Time of Stonehenge, Edimburgo.

COLES, J. M. (1968/69): "Scottish Early Bronze Age Metalwork", Proc. Soc. Ant. Scotland, 101, 1-110. 
COMENDADOR REY, B. (1997): "Las representaciones de armas y sus correlatos metálicos", F. J. Costas Goberna / J. M. Hidalgo Cuñarro (coord.), Los motivos de fauna y armas en los grabados prehistóricos del continente europeo, Vigo, 115-130.

COMENDADOR REY, B. (1998): "Los inicios de la metalurgia en el Noroeste de la Península Ibérica”, Brigantium, 11, 1-262.

COMENDADOR REY, B. (2001): "A Idade do Bronze en Galicia: balance e perspectivas", J. M. Eguileta / L. Orero / L. Castro (eds.), Arqueoloxía prehistórica na terra de Celanova, Celanova, 103-130.

COSTAS GOBERNA, F. J. / FERNÁNDEZ PINTOS, J. / GOBERNA PENA, J. L. / FERNÁNDEZ DÍAZ, M. A. (1984): Petroglifos del litoral sur de la Ría de Vigo, Publicaciones del Museo Municipal "Quiñones de León”, 8, Vigo.

COSTAS GOBERNA, F. J. / NOVOA ÁLVAREZ, P. / ALBO MORÁN, J. M. (1993/94): “Los grabados rupestres de armas de Pedra Ancha (Dumbria, A Coruña)", Brigantium, 8, 245-262.

CRIADO BOADO, F. / VÁZQUEZ VARELA, J. M. (1982): La cerámica campaniforme en Galicia, Cuadernos do Seminario de Sargadelos, 42, Sada.

CRUZ, D. J. da (1992): A mamoa 1 de Chã de Carvalhal no contexto arqueológico da Serra da Aboboreira, Coimbra.

CRUZ, D. J. da (1995): “Cronologia dos monumentos com tumulus do Noroeste peninsular e da Beira Alta", Estudos Pré-históricos, 3, 81-119.

DELIBES DE CASTRO, G. (1971): “Una necrópolis de inhumación individual de la Edad del Bronce en Villalmanzo (Burgos)", Bol. Seminario Estud. Arte, 37, 407-418.

DELIBES DE CASTRO, G. (1979): "Hallazgo campaniforme en Villaverde de Iscar, Segovia”, Bol. Seminario Estud. Arte, 45, 5-18.

DELIBES DE CASTRO, G. / FERNÁNDEZ MIRANDA, M. (1981): "La tumba de Celada de Roblecedo (Palencia) y los inicios del Bronce Antiguo en el valle medio y alto del Pisuerga", Trab. Prehist., 38, 153-192.

DUNWELL, A. J. / NEIGHBOUR, T. / COWIE, T. G. (1995): "A Cist Burial Adjacent to the Bronze Age Cairn at Cnip, Uig, Isle of Lewis", Proc. Soc. Ant. Scotland, 125, 279-288.
EGGERS, H. J. (1950): "Die vergleichend geographisch-kartographische Methode in der Urgeschichtsforschung", Arch. Geogr., 1, 1-3.

EOGAN, G. (1990): "Irish Megalithic Tombs and Iberia: Comparisons and Contrasts", Probleme der Megalithgräberforschung. Vorträge zum 100. Geburtstag von Vera Leisner, Madrider Forsch., 16, Berlín - Nueva York, 113-137.

ESTACIO DA VEIGA, S. P. Martins (1889): Antigüidades monumentães do Algarve III, Lisboa.

ESTACIO DA VEIGA, S.P. Martins (1891): Antigüidades monumentães do Algarve IV, Lisboa.

FABIÁN GARCÍA (1992): "El enterramiento campaniforme del túmulo 1 de Aldeagordillo (Ávila)", Bol. Seminario Estud. Arte, 58, 97-135.

FÁBREGAS VALCARCE, R. (1983): “Materiales líticos del Museo Provincial de Lugo: precisiones sobre la fase final de la cultura megalítica del N.O. peninsular", Bol. Mus. Prov. Lugo, 1, $31-46$.

FÁBREGAS VALCARCE, R. (1993): “Enterramientos tumulares en la Edad del Bronce? Nuevas evidencias para el Noroeste", Espacio, Tiempo y Forma, Serie I, 6, 181-204.

FÁBREGAS VALCARCE, R. (1995 a): "La realidad funeraria en el Noroeste del Neolítico a la Edad del Bronce", Arqueoloxía da morte na Península Ibérica desde as orixes ata o Medievo, Xinzo de Limia, 95-125.

FÁBREGAS VALCARCE, R. (1995b): "El fenómeno tumular en el Bronce del Noroeste", Actas del XXII Congreso Nacional de Arqueología I, Vigo 1993, Vigo, 85-91.

FÁBREGAS VALCARCE, R. (1998): A Idade do Bronce en Galicia: novas perspectivas, Cadernos do Seminario de Sargadelos, 77, La Coruña.

FERNÁNDEZ, A. / BELTRÁN, A. (1951): "Prospecciones en Alloza", Caesaraugusta, 1, $139 \mathrm{~s}$.

FORTES, J. (1906 a): “A sepultura da Quinta da Agua Branca”, Portugalia, 2, fasc. 2, 241-252.

FORTES, J. (1906 b): “La sépulture de Quinta da Agua Branca près Porto (Portugal)", Rev. Préhist., 1, 157-178.

GACHINA, J. (1997): "Inventaire des pointes de Palmela trouvées en France", Préhist. Sud 
Ouest, 4, 22-31.

GALLAY, G. (1970): "Steinkisten von Salvatierra de Tormes (Prov. Salamanca)", Madrider Mitt., $11,75-90$.

GALLAY, G. (1981): Die kupfer- und altbronzezeitlichen Dolche und Stabdolche in Frankreich, PBF, VI, 5, Munich.

GARCÍA ALÉN, A. / PEÑA SANTOS, A. de la (1980): Grabados rupestres de la provincia de Pontevedra, Pontevedra.

GARCÍA MARTÍNEZ, M. C. (1973): "Representacions de armas no arte rupestre galego", Cuad. Estud. Gallegos, 28, 111-127.

GARRIDO PENA, R. / ROJO GUERRA, M. A. / GARCÍA MARTÍNEZ DE LAGRÁN, I. (2005), "El Campaniforme en la Meseta central de la Península Ibérica", M. A. Rojo Guerra / R. Garrido Pena / I. García Martínez de Lagrán (eds.), El Campaniforme en la Península Ibérica y su contexto europeo, Valladolid, 411-456.

GERLOFF, S. (1975): The Early Bronze Age Daggers in Great Britain and a Reconsideration of the Wessex Culture, PBF, VI, 2, Munich.

GONZÁLEZ ALCALDE, J. / GARCÍA NAVAJOUBIERNA, I. (1996): "Las cistas de la Edad del Bronce de Salvatierra de Tormes (Salamanca)", Verdolay, 8, 31-35.

HARBISON, P. (1967): "Mediterranean and Atlantic Elements in the Early Bronze Age of Northern Portugal and Galicia", Madrider Mitt., 8, 100-122.

HARBISON, P. (1988): Pre Christian Ireland: From the First Settlers to the Early Celts, Londres.

HARRISON, R. J. (1974 a): “A Closed Find from Cañada Rosal, Prov. Sevilla, and Two Bell Beakers", Madrider Mitt., 15, 1974, 77-94.

HARRISON, R. J. (1974 b): "Ireland and Spain in the Early Bronze Age", Journal Royal Soc. Ant. Ireland, 104, 1974, 52-73.

HARRSION, R. J. (1980): The Beaker Folk: Copper Age Archaeology in Western Europe, Ancient Peoples and Places, 97, Londres.

HARRISON, R. J. / MEDEROS MARTÍN, A. (2001): "Bell Beakers and Social Complexity in Central Spain", F. Nicolis (ed.), Bell Beakers Today. Pottery, People, Culture, Symbols in
Prehistoric Europe. Proceedings of the International Colloquium Riva del Garda (Trento, Italy) 11-16 May 1998, Trento, 111-124.

HAVEL, J. (1978): "Pohr̄ební ritus kultury zvonocovitỹch pohárủ v C̄echách a na Moravē [The Burial Rite of the Bell Beaker Culture in Bohemia and Moravia]", Varia Archaeologica, I, Praehistorica, 7, Praga, 91-117.

IGLESIA, S. de la (1907): “Catálogo de la sección de protohistoria gallega de la colección de Santiago de la Iglesia", Almanaque de Ferrol para el año 1908, Ferrol, 59-67.

JALHAY, E. (1934): “A adaga da Quinta da Romeira", Brotéria, 19, 22-30.

JOCKENHÖVEL, A. (1991): "Räumliche Mobilität von Personen in der mittleren Bronzezeit des westlichen Mitteleuropa", Germania, 69, fasc. 1, 49-62.

JORGE, S. Oliveira (1986): Povoados da pré-história recente (III ${ }^{\circ}-$ inícios do $I I^{o}$ milénios $a$. C.) da região de Chaves - $V^{a} P^{a}{ }^{a}$ de Aguiar (Trásos-Montes ocidental), Oporto.

JORGE, S. Oliveira (1988): "Reflexões sobre a préhistória recente do norte de Portugal", Trab. Antr. e Etn., 28, fasc. 1/2, 85-112.

JORGE, S. Oliveira (1999): "Castelo Velho de Freixo de Numão (Vila Nova de Foz Côa, Portugal). Geschichte der Interpretationsversuche", Madrider Mitt., 40, 80-96.

KALB, Ph. / HÖCK, M. (1979): “Ausgrabungen in der Grabhügelnekropole Fonte da Malga (Viseu, Portugal)", Madrider Mitt., 20, 43-56.

LANTING, J. N. / BRINDLEY, A. L. (1999): "Fechando hueso cremado: la base científica", Trab. Prehist., 56, fasc. 2, 137-140.

LÓPEZ CUEVILLAS, F. (1925): “Os oujetos argáricos do Museu d'Ourense", Bol. Real Acad. Gallega, 20, 97-107.

LÓPEZ CUEVILLAS, F. (1933): "Prehistória de Melide", Terra de Melide, Santiago de Compostela, 33-134.

LÓPEZ CUEVILLAS. F. (1955): "El comienzo de la edad de los metales en el Noroeste peninsular", Cuad. Estud. Gallegos, 10, 5-39.

LÓPEZ CUEVILLAS, F (1956): “Un puñal argárico encontrado en una mamoa", Cuad. Estud. Gallegos, 11, 299 s.

LÓPEZ CUEVILLAS, F. (1959): "La época mega- 
lítica en el Noroeste de la Península", Caesaraugusta, 13/14, 21-77.

LÓPEZ CUEVILLAS, F. / BOUZA BREY, F. (1929): "Os oestrimnios, os saefes e a ofiolatría en Galiza”, Arquivos Seminario Estud. Galegos, 2, 27-193.

LÓPEZ CUEVILLAS, F. / BOUZA BREY, F. (1931): "La civilización neo-eneolítica gallega", Archivo Español Arte y Arqu., 7, 41-61.

LUENGO MARTÍNEZ, J. M. (1964/65): "Carnota (Coruña): Pedra Marrada”, Not. Arqu. Hispánico, 8/9, 347.

MACWHITE, E. (1951): Estudios sobre las relaciones atlánticas de la Península Hispánica en la Edad del Bronce, Disertaciones Matritenses, 2, Madrid.

MALUQUER DE MOTES, J. (1960): "Nuevos hallazgos de la cultura del vaso campaniforme en la Meseta", Zephyrus, 11, 119-130.

MARTÍN MORALES, C. / FERNÁNDEZ MIRANDA, M. / FERNÁNDEZ-POSSE, M. D. / GILMAN, A. (1993): "The Bronze Age of La Mancha", Antiquity, 67, 23-45.

MARTÍN VALLS, R. / DELIBES DE CASTRO, G. (1989): La cultura del vaso campaniforme en las campiñas meridionales del Duero: El enterramiento de Fuente-Olmedo (Valladolid), Monografías del Museo Arqueológico de Valladolid, 12, Valladolid.

MEIJIDE CAMESELLE, G. (1994): "El concepto de las relaciones atlánticas en la Edad del Bronce del Noroeste", L. Castro Pérez / S. Reboreda Morillo (eds.), Edad del Bronce: actas del curso de verano de la Universidad de Vigo, celebrado en Xinzo de Limia, 6/8 julio 1993, Xinzo de Limia, 195-231.

MEIJIDE CAMESELLE, G. (1995): "La necrópole del Bronce Inicial del Agro de Nogueira (Toques, La Coruña)", Actas del XXII Congreso Nacional de Arqueología II, Vigo 1993, Vigo, 85-88.

MONTEAGUDO, L. (1953): “Orfebrería del NW. hispánico en la Edad del Bronce”, Arch. Esp. Arqu., 26, 269-312.

MONTEAGUDO, L. (1981): "Koiné del Bronce Atlantico?", I. ${ }^{\circ}$ Coloquio Galaico-Minhoto, Ponte de Lima, 365-394.

MONTEAGUDO, L. / GARCÍA ALÉN, A. / LOIS MEIJOMIL, J. (1981): "El hacha de Salto (Rodeiro) y las primeras hachas de tope de dos asas en Europa", Mus. Pontevedra, 35, $117-162$.

MORÁN BARDÓN, C. (1930): "Excavaciones en los dólmenes de Salamanca", Memorias Junta Superior Excavaciones y Antigüedades, 113, Madrid.

MOUNT, C. (1995): "New Research in Irish Early Bronze Age Cemeteries", J. Waddell / E. Shee Twohig (eds.), Ireland in the Bronze Age. Proceedings of the Dublin Conference, April 1995, Dublin, 97-112.

NEEDHAM, S. (1988): "Selective Deposition in the British Early Bronze Age", World Arch., 20, 229-248.

NEEDHAM, S. (2000 a): "Power Pulses Across a Cultural Divide: Cosmologically Driven Acquisition Between Armorica and Wessex", Proc. Prehist. Soc., 66, 151-207.

NEEDHAM, S. (2000 b): "The Development of Embossed Goldwork in Bronze Age Europe", Ant. Journal, 80, 27-65.

NOGUEIRA, A. de Mello / ZBYSZEWSKI, G. (1943): "Túmulo da época do bronze", Comun. Serv. Geol. Portugal, 24, 95-97.

PAÇO, A. / FERREIRA, M. E. (1957): "Espada de cobre do Pinhal dos Melos (Fornos de Algodres)", Publicações do XXIII Congresso Luso-Espanhol VIII, Coimbra 1956, Coimbra, 5-12.

PEÑA SANTOS, A. de la (1980): "O tema da alabarda nos grabados rupestres galegos", Brigantium, 1, 49-69.

PEÑA SANTOS, A. de la (1985): "Las cistas de Gandón (Cangas de Morrazo, Pontevedra)", Mus. Pontevedra, 39, 77-94.

PINGEL, V. (1985): "Bemerkungen $\mathrm{zu}$ den Schatzfunden von Caldas de Reyes (Prov. Pontevedra)", Madrider Mitt., 26, 29-44.

PINGEL, V. (1992): Die vorgeschichtlichen Goldfunde der Iberischen Halbinsel, Madrider Forsch., 17, Berlin.

PRIETO MARTÍNEZ, M. P. (1999): "Caracterización del estilo cerámico de la Edad del Bronce en Galicia: cerámica campaniforme y cerámica no decorada", Complutum, 10, 71-90.

RODRÍGUEZ CASAL, A. A. (1983): “A mamoa de Monte Campelos e o seu enterramento secundario", Bol. Mus. Prov. Lugo, 1, 7-30. 
RODRÍGUEZ CASAL, A. A. (1989): La necrópolis megalítica de Parxubeira (San Fins de Eirón, Galicia), Monografías Urxentes do Museu, 4, La Coruña.

RODRÍGUEZ-COLMENERO, A. / DELIBES DE CASTRO, G. (1973): "Hallazgos prehistóricos en la provincia de Orense", Cuad. Estud. Gallegos, 28, 52-61.

RODRÍGUEZ-COLMENERO, A. / DELIBES DE CASTRO, G. (1976): “Una nueva necrópolis de cistas en el Noroeste peninsular", Letras Deusto, 6, fasc. 12, 181-186.

ROJO GUERRA, M. (1989): “El túmulo protohistórico del 'Paso de la Loba' (Huidobro, Burgos)", Trab. Prehist., 46, 99-116.

RUIZ-GÁLVEZ PRIEGO (1979): “El Bronce Antiguo en la fachada atlántica peninsular: un ensayo de periodización", Trab. Prehist., 36, 151-172.

RUIZ-GÁlVEZ PRIEGO (1984): La Península Ibérica y sus relaciones con el circulo cultural atlántico, Madrid.

RUIZ LARA, D. (1984/85): "La cultura del vaso campaniforme en la campiña de Córdoba: El hallazgo de La Rambla”, Corduba Arch., 15, 15-30.

SANCHES, M. de J. (1992): Pré-história recente no planalto mirandês (Leste de Trás-osMontes), Monografias Arqueológicas, 3, Oporto.

SANCHES, M. de J. / BOTELHO, I. J. S. Teles M. / SILVA, M. M. Santos (1990/91): "Mamoa 1 da Pedreira, S. Pedro de Vale do Conde (Marmelos, Mirandela). Excavação de emergência”, Portugalia, 11/12, 39-52.

SANCHES, M. de J. (1997): Pré-história recente de Trás-os-Montes e Alto Douro ( $O$ abrigo do Buraco da Pala no contexto regional), SPAE Serie Textos, 1, Oporto.

SCHUBART, H. (1971): "O horizonte de Ferradeira: sepulturas do eneolítico final no sudoeste da Península Ibérica", Rev. Guimarães, 81, 189-215.

SCHUBART, H. (1975): Die Kultur der Bronzezeit im Südwesten der Iberischen Halbinsel, Madrider Forsch., 9, Berlin.

SILVA, F. A. Pereira da (1997): "Contextos funerários da Idade do Bronze nos planaltos centrais do Centro-Norte litoral português: Tradição ou inovação?", Actas del II Congreso de
Arqueología Peninsular II: Neolítico, Calcolítico y Bronce, Zamora 1996, Zamora, 605-620.

SILVA, A. Coelho F. da / LOPES, A. Baptista / MACIEL, T. Pinheiro (1981): “A necrópole do Bronze Inicial da Chã de Arefe (Durrães, Barcelos) - Primeira notícia", Arquivo Alto Minho, 36, 49-61.

SILVA, E. J. Lopes da / CUNHA, A. M. C. Leite da (1986): "As gravuras rupestres do Monte da Lage (Valença)”, Arqueologia, 13, 143-158.

SPINDLER, K. (1993): "Eine goldene Armschutzplatte aus Portugal”, Acta Praehist. et Arch., 25, 56-62.

SUÁREZ OTERO, J. (2002): “Die Bronzezeit in Galicien", Madrider Mitt., 43, 1-21.

SUÁREZ OTERO, J. (2005): “Una nueva región campaniforme: el Noroeste hispánico. Una propuesta de síntesis desde la casuistica gallega”, M. A. Rojo Guerra / R. Garrido Pena / I. García Martínez de Lagrán (eds.), El Campaniforme en la Península Ibérica y su contexto europeo, Valladolid, 177-195.

TAYLOR, J. J. (1978): “The Relationship of Early Bronze Age Goldwork to Atlantic Europe", The Origins of Metallurgy in Atlantic Europe. Proceedings of the Fifth Atlantic Colloquium. Dublin, 30th March to 4th April 1978, Dublin, 229-250.

VAQUERO LASTRES, J. (1995 a): "Ver y moverse: túmulos en el NW peninsular", Actas del XXII Congreso Nacional de Arqueología I, Vigo 1993, Vigo, 399-404.

VAQUERO LASTRES, J. (1995 b): “Túmulos tardios en el NW. RB1: estructuras", Actas del XXII Congreso Nacional de Arqueología I, Vigo 1993, Vigo, 405-410.

VÁZQUEZ VARELA, J. M. (1980 a): "Enterramientos en cista de la Edad del Bronce en Galicia”, Pontevedra, 0, 23-40.

VÁZQUEZ VARELA, J. M. (1980b): “Cistas decoradas en Galicia: una nueva manifestación artística de la Edad del Bronce”, Brigantium, 1, 41-48.

VÁZQUEZ VARELA, J. M. (1985/86): "Nueva cista decorada del Bronce Inicial de Galicia", Pontevedra Arqu., 2, 91-95.

WELS-WEYRAUCH， U. (1989): "Fremder Mann?", Germania, 67, fasc. 1, 162-168. 